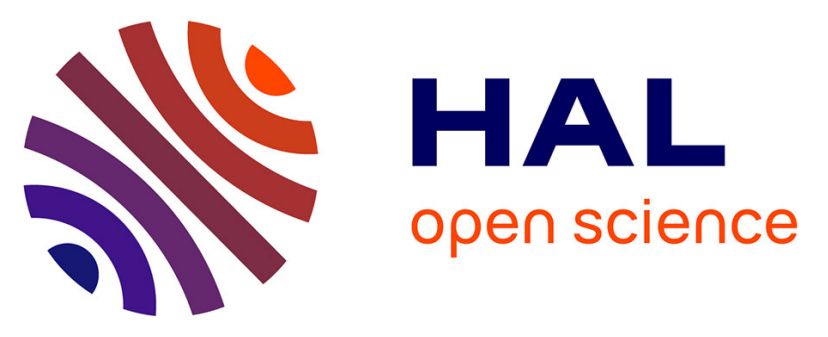

\title{
Efficient Synthesis of Snowman- and Dumbbell-like Silica/Polymer Anisotropic Heterodimers through Emulsion Polymerization Using a Surface-Anchored Cationic Initiator
}

Julien Parvole, Isabelle Chaduc, Komla Ako, Olivier Spalla, Antoine Thill, Serge Ravaine, Etienne Duguet, Muriel Lansalot, Elodie Bourgeat-Lami

\section{To cite this version:}

Julien Parvole, Isabelle Chaduc, Komla Ako, Olivier Spalla, Antoine Thill, et al.. Efficient Synthesis of Snowman- and Dumbbell-like Silica/Polymer Anisotropic Heterodimers through Emulsion Polymerization Using a Surface-Anchored Cationic Initiator. Macromolecules, 2012, 45 (17), pp.7009-7018. 10.1021/ma301355g . hal-00733814

\section{HAL Id: hal-00733814 \\ https://hal.science/hal-00733814}

Submitted on 22 Dec 2021

HAL is a multi-disciplinary open access archive for the deposit and dissemination of scientific research documents, whether they are published or not. The documents may come from teaching and research institutions in France or abroad, or from public or private research centers.
L'archive ouverte pluridisciplinaire HAL, est destinée au dépôt et à la diffusion de documents scientifiques de niveau recherche, publiés ou non, émanant des établissements d'enseignement et de recherche français ou étrangers, des laboratoires publics ou privés. 


\section{Efficient synthesis of snowman- and dumbbell-like silica/polymer anisotropic heterodimers through emulsion polymerization using a surface-anchored cationic initiator}

\begin{tabular}{|r|l|}
\hline Journal: & Macromolecules \\
\hline Manuscript ID: & ma-2012-01355g.R1 \\
\hline Manuscript Type: & Article \\
\hline Date Submitted by the Author: & 10 -Aug-2012 \\
\hline Complete List of Authors: & $\begin{array}{l}\text { Chaduc, Isabelle; UMR 5265, Chimie Catalyse Polymères et Procédés } \\
\text { (C2P2), } \\
\text { Parvole, Julien; Université Lyon1 - CPE Lyon, C2P2, LCPP group } \\
\text { Ako, Komla; CEA, CEA/IRAMIS/SIS2M } \\
\text { Spalla, Olivier; CEA, CEA/IRAMIS/SIS2M } \\
\text { Thill, Antoine; CEA, DSM/DRECAM } \\
\text { Ravaine, Serge; CRPP, } \\
\text { Duguet, Etienne; ICMCB, University of Bordeaux } \\
\text { Lansalot, Muriel; UMR 5265, Chimie Catalyse Polymères et Procédés } \\
\text { (C2P2) } \\
\text { Bourgeat-Lami, Elodie; UMR 5265, Chimie Catalyse Polymères et Procédés } \\
\text { (C2P2) }\end{array}$ \\
\hline
\end{tabular}




\title{
Efficient synthesis of snowman- and dumbbell-like
}

\author{
silica/polymer anisotropic heterodimers through
} emulsion polymerization using a surface-anchored

\section{cationic initiator.}

\author{
Julien Parvole, ${ }^{1}$ Isabelle Chaduc, ${ }^{1}$ Komla Ako, ${ }^{2}$ Olivier Spalla, ${ }^{2}$ Antoine Thill, ${ }^{2}$ Serge Ravaine, ${ }^{3}$ \\ Etienne Duguet, ${ }^{4}$ Muriel Lansalot, ${ }^{1}$ Elodie Bourgeat-Lami ${ }^{2}$ \\ ${ }^{1}$ Université de Lyon, Univ. Lyon 1, CPE Lyon, CNRS UMR5265, Laboratoire de Chimie, \\ Catalyse, Polymères et Procédés (C2P2), LCPP group, 43 Bd. du 11 Novembre 1918, 69616 \\ Villeurbanne, France. ${ }^{2} \mathrm{CEA}$, IRAMIS, Laboratoire Interdisciplinaire sur l'Organisation \\ Nanométrique et Supramoléculaire 91191 Gif-sur-Yvette, France. ${ }^{3}$ CNRS, Univ. Bordeaux, \\ CRPP, UPR 8641, 33600 Pessac, France. ${ }^{4}$ CNRS, Univ. Bordeaux, ICMCB, UPR 9048, 33600 \\ Pessac, France.
}

Corresponding author: bourgeat@lcpp.cpe.fr

KEYWORDS: silica, emulsion polymerization, cationic initiator, hybrid, dissymmetrical, Janus, particle morphology. 


\begin{abstract}
We report a novel original synthetic route to hybrid dissymmetrical snowmanand dumbbell-like silica/polymer colloidal particles through emulsion polymerization of methyl methacrylate (MMA) or styrene using a bicationic initiator previously anchored on the silica surface. Anisotropic particles with a polymer nodule attached to a single silica sphere were successfully obtained in high yield in the presence of a mixture of non-ionic and anionic surfactants under optimized initiator concentration conditions. Both non-ionic surfactant and cationic initiator were key ingredients in controlling particle morphology as evidenced by transmission electron microscopy. By optimizing the silica content and the surfactant composition, latexes with a latex-to-silica seed number ratio $\left(\mathrm{N}_{\text {Latex }} / \mathrm{N}_{\text {Silica }}\right)$ close to 1 were produced using either MMA or styrene as monomers. Their shapes evolved from snowman- and reverse snowman- at low and high conversions to dumbbell-like for intermediate conversions. The evolution of particle morphology with time provided insights into the mechanism of composite particles formation.
\end{abstract}

\title{
TOC GRAPHIC
}
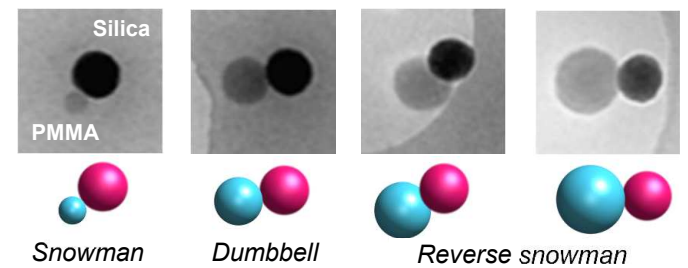

Monomer to polymer conversion 


\section{INTRODUCTION}

Organic/inorganic particles are finding increasing attention in the recent literature because of their potential applications in materials science, biology and physics. ${ }^{1}$ Such particles can be obtained by a variety of methods and can exhibit a variety of shapes, compositions and functionalities. ${ }^{2}$ Among them, dissymmetrical colloidal particles that have non-uniform bulk or surface distributions (so-called Janus particles) have attracted considerable interest as these anisotropic nano-objects can find applications in the elaboration of electronic displays, ${ }^{3}$ as building blocks for photonic crystals with novel symmetries, ${ }^{4-6}$ in biology ${ }^{7}$ or as solid surfactants for the stabilization of complex media. ${ }^{8,9}$ It has been suggested for instance that Janus particles can adsorb at liquid/liquid interfaces, and be efficient emulsion stabilizers. ${ }^{10-13}$

A variety of strategies for fabricating dissymmetrical Janus particles has appeared in the literature including emulsion templating, ${ }^{14}$ surface templating, ${ }^{15}$ controlled phase separation in seeded polymerization techniques, ${ }^{16-22}$ partial shielding of particles, ${ }^{23-26}$ microcontact printing, ${ }^{27}$ or controlled surface nucleation. ${ }^{28}$ However, as recently reviewed, most of these methods are template-assisted or require a multi-step procedure. ${ }^{29-32}$ Moreover, these processes generally lead to small amount of a given type of particle morphology and requires a sorting process to produce homogeneous samples. In addition, most of them work only if the seed particles are at least several micrometers in size and mainly concern the elaboration of polymer/polymer or inorganic/inorganic dimers.

We recently demonstrated a one-pot scalable process capable of generating dissymmetrical (both in shape and composition) organic/inorganic particles in high yields. ${ }^{33-36} \mathrm{In}$ this process, the surface of a silica seed was previously treated by low amounts of methacryloxyalkyltrimethoxy silane or of a poly(ethylene oxide)-based macromonomer, in order to create reactive 
(co)polymerizable loci promoting the surface capture of the growing macromolecules, and therefore the nucleation of the polymer latex particles. The resulting anisotropic colloids had dumbbell or snowman shapes and carried anionic surface charges homogeneously distributed on the organic and inorganic parts of the dissymmetrical particles. Although this process could potentially be generalized to other organic and inorganic materials, until now we only investigated styrene as monomer.

Herein, we report a new synthetic method based on emulsion polymerization for the preparation of large amounts of polymer/silica dissymmetrical nanoparticles. These particles consist of poly(methyl methacrylate) (PMMA) or polystyrene (PS) latex particles attached to a single anionic silica sphere. Our strategy is based on electrostatic interaction between a cationic azo initiator and silica particles followed by in situ emulsion polymerization of the corresponding monomer in the presence of the initiator-anchored particles as schematically illustrated below.

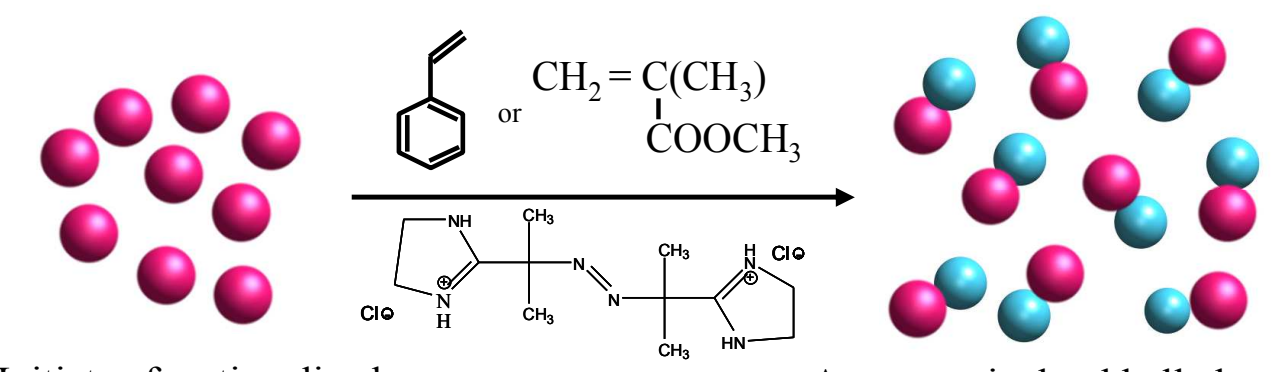

Initiator-functionalized aqueous silica sol
ADIBA

$60^{\circ} \mathrm{C}$, water
Asymmetric dumbbell-shaped silica/polymer heterodimers

Scheme 1. Schematic illustration of the synthetic strategy used in this work to prepare dissymmetrical silica/polymer heterodimers. 
While the use of a cationic initiator to give colloidal nanocomposites by emulsion polymerization has been already reported in the literature, ${ }^{37-41}$ to the best of our knowledge, there is no report describing the synthesis of dissymmetrical colloidal particles by this technique. The current strategy allows elaborating snowman- and dumbbell-like silica/polymer anisotropic particles in high yield. The influence of various synthesis parameters such as the initiator concentration, the silica content or the nature of the surfactant have been thoroughly investigated, the emphasis being placed on their effect on particle morphology and colloidal stability.

\section{EXPERIMENTAL}

Materials. Styrene (99+\%, Sigma) and methyl methacrylate (MMA, 99+\%, Sigma) were used as received. Synperonic ${ }^{\circledR}$ NP30 (Fluka) and sodium dodecyl sulfate (SDS, Acros Organic, 99\%) were used as non-ionic and anionic surfactants, respectively. The initiators: 2,2'-azobis[2-methyl$N$-(2-hydroxyethyl) propionamide] (VA86, Wako chemicals Gmbh) and 2,2'-azobis( $N, N^{\prime}$ dimethylene isobutyramidine) dihydrochloride (ADIBA, Wako chemicals Gmbh) were used without further purification. All chemical structures are shown in the Supporting Information (Figure S1). The aqueous silica sol (Klebosol ${ }^{\circledR}$ 30R50) used in this work was kindly supplied by Clariant (France) as a $31.5 \%$ solids colloidal suspension of particles with an average hydrodynamic diameter $\mathrm{D}_{z}$ of $86 \mathrm{~nm}$ as determined by dynamic light scattering (DLS) (Table 1). As shown by transmission electron microscopy (TEM), the suspension was bimodal in size with a dominant population of particles centered at $81.8 \mathrm{~nm}$ and a minor population of smaller particles centered at $40 \mathrm{~nm}$ giving a global $D_{n}$ of $77 \mathrm{~nm}\left(D_{w}=83 \mathrm{~nm}\right)$. The TEM image and the 
histogram of size distribution are shown in the Supporting Information (Figure S2). All experiments were performed with deionized water (PureLab Classic UV, Elga Lab Water).

Table 1. Characteristics of the Klebosol ${ }^{\circledR} 30$ R50 colloidal silica sol.

\begin{tabular}{|c|c|c|c|c|}
\hline $\begin{array}{l}{\left[\mathrm{SiO}_{2}\right]} \\
\left(\mathrm{wt} \% / \text { g. } \mathrm{L}^{-1}\right)^{\mathrm{a}}\end{array}$ & $\mathbf{D}_{\mathrm{z}}(\mathrm{nm}) / \sigma^{\mathrm{b}}$ & $\begin{array}{l}\mathbf{D}_{\mathbf{n}}(\mathbf{n m}) / \\
\mathbf{D}_{\mathbf{w}} / \mathbf{D}_{\mathbf{n}} \mathbf{c}\end{array}$ & pH & $\begin{array}{l}\text { Specific surface } \\
\text { area }\left(m^{2} \cdot g^{-1}\right)^{d}\end{array}$ \\
\hline $31.5 / 460$ & $86 / 0.04$ & $77 / 1.08$ & 9.8 & 50 \\
\hline
\end{tabular}

${ }^{a}$ Determined by gravimetric analysis. ${ }^{b} Z$-average particle diameter and poly value measured by DLS. ${ }^{c}$ Number average diameter and polydispersity index determined by TEM by counting more than 500 silica particles. ${ }^{\mathrm{d}}$ Supplier data record.

Adsorption isotherm of ADIBA on silica. $10 \mathrm{~mL}$ of a 60 g. $\mathrm{L}^{-1}$ aqueous suspension of silica was equilibrated with a known amount of an aqueous solution of ADIBA $\left(10\right.$ g. $\left.\mathrm{L}^{-1}\right)$. A known volume of deionized water was then added to cover a range of ADIBA concentrations comprised between 0 and 0.2 g. $\mathrm{L}^{-1}$ (i.e. from 0 to $0.25 \mu \mathrm{mol} . \mathrm{m}^{-2}$ ) while fixing the silica concentration to 50 g. $\mathrm{L}^{-1}$. The mixtures were stirred at room temperature for 12 hours and then centrifuged at 21000 rpm for 2 hours. The supernatants were analyzed by UV-visible spectroscopy (Jasco Instrument, Model V-530, France) and the ADIBA concentrations were determined from a previously-made calibration curve $\left(\lambda_{\max }=220 \mathrm{~nm}\right)$. The amounts of adsorbed ADIBA, Qe $\left(\mathrm{mg} \cdot \mathrm{g}^{-1}\right)$, were determined according to:

$$
\mathrm{Q}_{\mathrm{e}}\left(\mathrm{mg} \cdot \mathrm{g}^{-1}\right)=\frac{\left(\mathrm{C}_{0}-\mathrm{C}_{\mathrm{e}}\right) \mathrm{V}}{\mathrm{m}} \times 1000
$$

where $C_{0}\left(\mathrm{~g} . \mathrm{L}^{-1}\right)$ is the initial ADIBA concentration, $C e\left(\mathrm{~g} . \mathrm{L}^{-1}\right)$ designates the ADIBA equilibrium concentration in the supernatant, $V(\mathrm{~L})$ is the volume of solution and $m(\mathrm{~g})$ is the mass of silica. The adsorbed amount per unit surface area is then given by: 
Adsorbed amount $\left(\mu \mathrm{mol} . \mathrm{m}^{-2}\right)=\frac{Q_{e} \times 1000}{S_{\text {spec }} M_{w}}$

where $\mathrm{S}_{\mathrm{spec}}\left(\mathrm{m}^{2} \cdot \mathrm{g}^{-1}\right)$ is the silica specific area and $\mathrm{M}_{\mathrm{w}}\left(\mathrm{g} \cdot \mathrm{mol}^{-1}\right)$ is the molar mass of ADIBA. The procedure was repeated in a similar way for initial silica concentrations of 10 and 30 g.L ${ }^{-1}$.

Particle synthesis. Unless otherwise stated, emulsion polymerizations were carried out in batch at $60^{\circ} \mathrm{C}$ under nitrogen atmosphere in a $300 \mathrm{~mL}$ glass reactor fitted with a condenser and a nitrogen gas inlet in the presence of the initiator-functionalized silica particles. Adsorption of the bicationic initiator was performed at room temperature under inert atmosphere and constant stirring by adding a given amount of a solution of the initiator in deionized water to the dilute silica sol. Degassing of the suspension was carried out for $1 \mathrm{~h}$. Then, the degassed monomer and a degassed solution of surfactants in deionized water were added at once before increasing the temperature to start polymerization. To prevent composite particles aggregation after polymerization, a shot of anionic surfactant (corresponding to a final concentration of 2 g.L $\mathrm{L}^{-1}$ ) was introduced in the latex suspension at the end of the reaction before further characterizations. The experimental conditions of the MMA and styrene polymerizations performed in this study are displayed in Tables 2 and 3, respectively. 
Table 2. Summary of experimental conditions and characterizations of the MMA emulsion polymerizations performed in this study.

\begin{tabular}{llllll}
\hline Entry & {$\left[\mathbf{S i O}_{2}\right]\left(\mathbf{g . L}^{-\mathbf{1}}\right)$} & $\mathbf{N P 3 0} / \mathbf{S D S}(\mathbf{w t} / \mathbf{w t})$ & Conversion $(\%)$ & $\mathbf{N}_{\text {Latex }} / \mathbf{N}_{\text {Silica }}$ & $\mathbf{N}_{\text {Latex }} \mathbf{L}^{\mathbf{- 1}}$ \\
\hline $1^{\mathrm{a}}$ & 50 & $98 / 2$ & 60 & 0.25 & $2.610^{16}$ \\
2 & 50 & $98 / 2$ & 98 & 0.85 & $8.910^{16}$ \\
\hline 3 & 50 & $100 / 0$ & Unstable & $/$ & $/$ \\
4 & 50 & $99 / 1$ & 50 & 0.60 & $6.310^{16}$ \\
5 & 50 & $97 / 3$ & 95 & 0.90 & $9.410^{16}$ \\
\hline 6 & 110 & $0 / 100$ & 100 & 1.05 & $2.410^{17}$ \\
\hline 7 & 10 & $98 / 2$ & 88 & 3.00 & $6.310^{16}$ \\
8 & 30 & $98 / 2$ & 98 & 1.20 & $7.510^{16}$ \\
9 & 40 & $98 / 2$ & 99 & 0.96 & $8.110^{16}$ \\
10 & 90 & $98 / 2$ & $60^{\mathrm{b}}$ & 0.55 & $1.010^{17}$ \\
\hline
\end{tabular}

The initiator, surfactant and monomer concentrations were fixed to $0.1,3$ and 100 g.L $^{-1}$, respectively. ADIBA was used as initiator in all experiments except for run $1 .{ }^{a}$ Initiator $=$ VA86. ${ }^{\mathrm{b}}$ Unstable latex for conversions higher than $60 \%$. Reaction temperature $=60^{\circ} \mathrm{C}$ except for run 1 $\left(\mathrm{T}=70^{\circ} \mathrm{C}\right) \cdot \mathrm{pH}=9.1$.

Table 3. Summary of experimental conditions and characterizations of all the styrene emulsion polymerizations performed in this study.

\begin{tabular}{|c|c|c|c|c|c|}
\hline Entry & {$\left[\mathrm{SiO}_{2}\right]\left(\mathrm{g} . \mathrm{L}^{-1}\right)$} & NP30/SDS (wt/wt) & Conversion (\%) & $\mathbf{N}_{\text {Latex }} / \mathbf{N}_{\text {Silica }}$ & $\mathbf{N}_{\text {latex }} \cdot \mathrm{L}^{-1}$ \\
\hline 1 & 50 & $98 / 2$ & 90 & 1.60 & $1.710^{17}$ \\
\hline 2 & 90 & $98 / 2$ & 60 & 1.25 & $2.410^{17}$ \\
\hline 3 & 50 & $99 / 1$ & 50 & 1.15 & $1.210^{17}$ \\
\hline 4 & 60 & $99 / 1$ & 50 & 1.10 & $1.210^{17}$ \\
\hline 5 & 90 & $99 / 1$ & $35^{\mathrm{a}}$ & 1.05 & $2.010^{17}$ \\
\hline
\end{tabular}
respectively. Reaction temperature $=60^{\circ} \mathrm{C} . \mathrm{pH}=9.1$. ${ }^{\mathrm{a}}$ Unstable latex for conversions higher than $35 \%$. 
Characterizations. Monomer consumption was followed by gravimetric analysis of samples withdrawn from the polymerization medium at different times. The $Z$-average hydrodynamic diameter $\left(D_{z}\right)$ was measured by DLS (Zetasizer Nano ZS from Malvern Instruments), and the data were collected using the fully automatic mode of the Zetasizer system. At least 3 measurements were performed for each sample. The broadness of the distribution was given by a dimensionless number called poly value $(\sigma)$ determined from the autocorrelation function using the second-order method of cumulant analysis. ${ }^{42}$ For a monodisperse sample, the $\sigma$ value should theoretically be zero. In practice, a $\sigma$ value for a "monodisperse" latex lies between 0 and 0.05 . Aqueous electrophoresis measurements (zeta potential) were also conducted using the same Zetasizer Nano-ZS instrument, in the presence of $1 \mathrm{mM} \mathrm{KCl}$ as background salt.

TEM analyses were carried out at the Centre Technologique des Microstructures $(\mathrm{CT} \mu)$, Claude Bernard University, Villeurbanne, France. A drop of the diluted latex suspension was deposited on a carbon/formvar-coated copper grid and allowed to evaporate before observation with a Philips CM120 'Cryo' microscope operating at $80 \mathrm{kV}$, under low dose conditions. In order to preserve particle shape (PMMA undergoes degradation under electron beam irradiation), we used an alternative technique that consists in depositing a drop of the latex suspension on a continuous carbon film, blotting the water in excess and mounting the dry specimen on the Gatan holder at room temperature. Once transferred in the microscope, the holder was cooled down to $180^{\circ} \mathrm{C}$, and the specimen were observed as indicated above. The number- and mass-average particle diameter ( $D_{n}$ and $D_{w}$, respectively) as well as the particle diameter dispersity $\left(D_{w} / D_{n}\right)$ were determined using AnalySIS software (Soft Imaging System).

The number ratio of polymer (PMMA or PS) latex particles to silica particles, $\mathrm{N}_{\text {Latex }} / \mathrm{N}_{\text {Silica }}$, was determined through statistical analysis of the TEM images by counting manually the number 
of latex particles and the number of silica particles, and making the ratio. Silica and polymer particles show significantly different contrasts and can be thus unambiguously identified on the micrographs. The total number of latex particles per latex volume was then deduced from the silica particles number, $\mathrm{N}_{\text {Silica. }} \cdot \mathrm{L}^{-1}$, according to: $\mathrm{N}_{\text {Latex }} \cdot \mathrm{L}^{-1}=\mathrm{R} \times \mathrm{N}_{\text {Silica. }} \mathrm{L}^{-1}$ with:

$$
\mathrm{N}_{\text {Silica }} \cdot \mathrm{L}^{-1}=\frac{\mathrm{C}_{\text {Silica }} \times 6 \times 10^{21}}{\pi \times \rho_{\text {Silica }} \times D_{\text {Silica }}^{3}}
$$

where $\mathrm{C}_{\text {Silica }}\left(\mathrm{g} . \mathrm{L}^{-1}\right), \rho_{\text {Silica }}\left(\mathrm{g} . \mathrm{cm}^{-3}\right)$ and $\mathrm{D}_{\text {Silica }}(\mathrm{nm})$ are the concentration, the density and the number average TEM diameter of the silica particles, respectively.

In order to provide a more reliable analysis of particle size and morphology, some selected samples were also observed in their natural hydrated environment using cryogenic TEM (cryoTEM). According to the method described elsewhere, ${ }^{43}$ thin liquid films of the suspensions were formed on 300 Mesh holey carbon films (Agar Scientific, UK) and quench-frozen in liquid ethane using a homemade workstation. The specimens were then mounted on a precooled Gatan 626 specimen holder, transferred in the microscope and observed as described previously. This method allowed us to determine the $\mathrm{N}_{\text {Latex }} / \mathrm{N}_{\text {Silica }}$ ratio from the average diameters of the silica and latex particles determined directly on the cryo-TEM micrographs, according to:

$$
\mathrm{N}_{\text {Latex }} / \mathrm{N}_{\text {Silica }}=\left(\frac{C_{\text {Polymer }}}{C_{\text {Silica }}}\right) \times\left(\frac{d_{\text {Silica }}}{d_{\text {Polymer }}}\right) \times\left(\frac{D_{\text {Silica }}}{D_{\text {Latex }}}\right)^{3}
$$

where $\mathrm{C}_{\text {Silica }}$ and $\mathrm{C}_{\text {Polymer }}\left(\mathrm{g} . \mathrm{L}^{-1}\right)$ are the silica and polymer concentrations, respectively; $\mathrm{d}_{\text {Silica }}$ and $\mathrm{d}_{\text {Polymer }}\left(\mathrm{g}_{\mathrm{cm}} \mathrm{cm}^{-3}\right)$ are the silica and polymer mass densities, respectively, and $\mathrm{D}_{\text {Silica }}$ and $\mathrm{D}_{\text {Latex }}$ (nm) are the diameters of the silica and latex particles determined by TEM, respectively. A minimum of 500 particles was counted for each batch.

Small and ultra small angle X-ray scattering (SAXS and USAXS) diagrams were obtained using two set-ups. SAXS and USAXS are using a $\mathrm{Cu}$ rotating anode, delivering X-ray of 
wavelength $0.154 \mathrm{~nm}$. The SAXS instrument is a pinhole camera using a 2D detector and has a q-range 0.01-0.6 $\AA^{-1}$. The USAXS instrument is based on two channels-cut coupled angular detection. The q range is $0.0003-0.03 \AA^{-1}$. The samples were measured in cells with kapton windows on both instruments.

\section{RESULTS AND DISCUSSION}

\section{Effect of the nature of the initiator}

Preliminary experiments were carried out to demonstrate the importance of the nature of the initiator in the successful formation of composite latex particles. The silica concentration was arbitrarily fixed at 50 g. $\mathrm{L}^{-1}$ (i.e., $50 \mathrm{wt} \%$ based on monomer) while the initiator concentration was adjusted to $0.1 \mathrm{~g} . \mathrm{L}^{-1}$ in order to prevent silica particles aggregation. This point will be discussed in details in the following section. Two different initiators were compared: a non-ionic (VA86) and a cationic one. Their chemical structures are shown in the Supporting Information (Figure S1). Instead of using 2,2'-azobis(2-amidinopropane) dihydrochloride (AIBA) as cationic initiator as usually reported in the literature, we selected the less conventional ADIBA bicationic azo initiator as the later contains heterocyclic amidine groups that are much less prone to hydrolysis at prolonged heating and prolonged exposure to alkaline media than the aliphatic amidine groups of AIBA. ${ }^{44-46}$ Figure 1 shows the particle morphology obtained in the presence of VA86 and ADIBA, respectively, under otherwise identical experimental conditions using MMA as monomer (entries 1 and 2 in Table 2). When VA86 was used as initiator, the PMMA latex particles and the silica spheres clearly appeared apart from each other indicating their absence of interaction. In contrast, the polymerization initiated by ADIBA resulted in PMMA 
latex particles (in grey) attached to a single silica bead (in dark) forming dumbbell-shaped colloids (pointed to by black arrows). A statistical analysis performed on around 200 particles and several TEM pictures of the same sample gave an average $\mathrm{N}_{\text {Latex }} / \mathrm{N}_{\text {Silica }}$ number ratio of 0.85 for this particular experiment (Table 2). Hence, in agreement with this statistical estimation, isolated silica particles could be also occasionally seen (see black circles in Figure 1b).

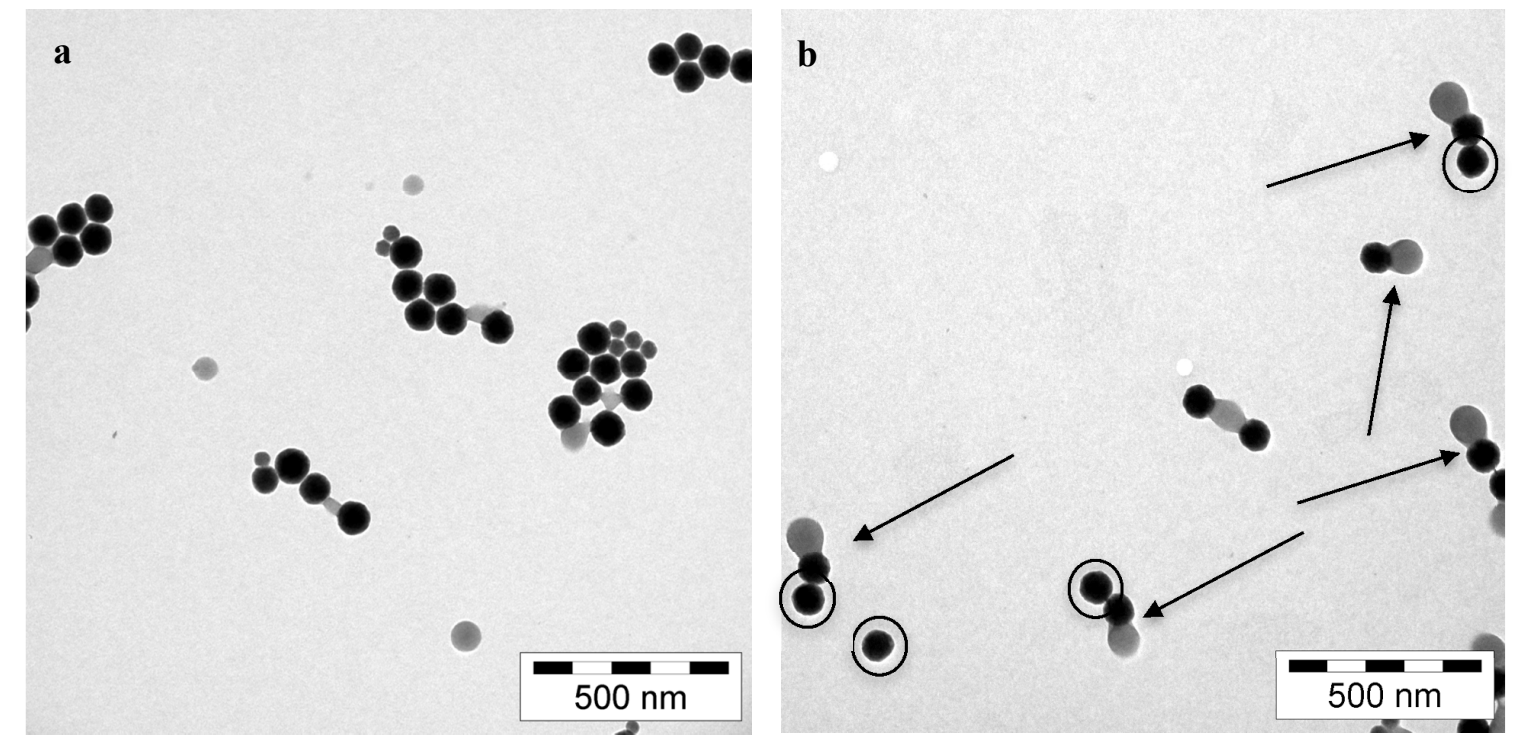

Figure 1. TEM images of silica/PMMA nanocomposite latexes synthesized using a) a non-ionic (VA86) and b) a cationic (ADIBA) initiator (entries 1 and 2 in Table 2). Arrows point to the silica/PMMA dissymmetrical particles. Black circles show isolated silica particles.

These preliminary experiments demonstrate that the bicationic ADIBA initiator plays a determining role in the formation of silica/PMMA colloidal nanocomposites through emulsion polymerization promoting the formation of polymer on the mineral seed presumably by means of electrostatic interactions. Indeed, since silica carries negative charges at $\mathrm{pH}=9.1$, electrostatic 
attraction takes place between the silica surface and the cationic amidinium groups of the diazoic compound. ${ }^{37,38}$ The adsorbed ADIBA molecules can thus initiate the polymerization leading to the formation of polymer nodules on the silica surface. Such electrostatic effects between cationic initiators and inorganic surfaces have already been reported in the literature. For example, AIBA has been shown to interact with titanium dioxide pigments, ${ }^{47}$ clay substrates ${ }^{41,48}$ or mica, ${ }^{49}$ and was used to initiate the polymerization of a variety of monomers either in solution or in emulsion resulting in the formation of composite particles. As far as emulsion polymerization and silica are concerned, raspberry (or inverted raspberry)-like morphologies characterized by polymer spheres surrounded by small silica particles (or vice-versa) have been mainly observed. ${ }^{37-40}$ Core-shell morphologies were also reported by Luna-Xavier et al. for very large silica particles in the presence of a non-ionic surfactant. ${ }^{37}$ To generate dissymmetrical colloids that associate one silica particle to a single polymer nodule, some specific requirements are to be fulfilled. First, as we already mentioned, the association of both materials should rely on some favorable interactions between the cationic initiator and the negatively charged silica particles. Second, the ratio between the amounts of both types of particles, $\mathrm{N}_{\text {Latex }} / \mathrm{N}_{\text {Silica, }}$, should be as close as possible to 1 . Last, special care should be taken to preserve colloidal stability of both silica and composite latex suspensions before and during polymerization as initiator adsorption may strongly affect such colloidal stability. In the following sections, we discuss each of these aspects in details. 


\section{Study of the interaction between ADIBA and the silica sol}

As mentioned above, selecting an appropriate initiator is essential to control particle morphology. Therefore, studying the interaction between ADIBA and the silica particles is of primary importance for an accurate understanding of the underlying mechanism governing dissymmetrical particles formation. Figure 2 shows the isotherm for adsorption of ADIBA onto the silica sol at a fixed concentration of 50 g. $\mathrm{L}^{-1}$ and $\mathrm{pH} 9.1$.

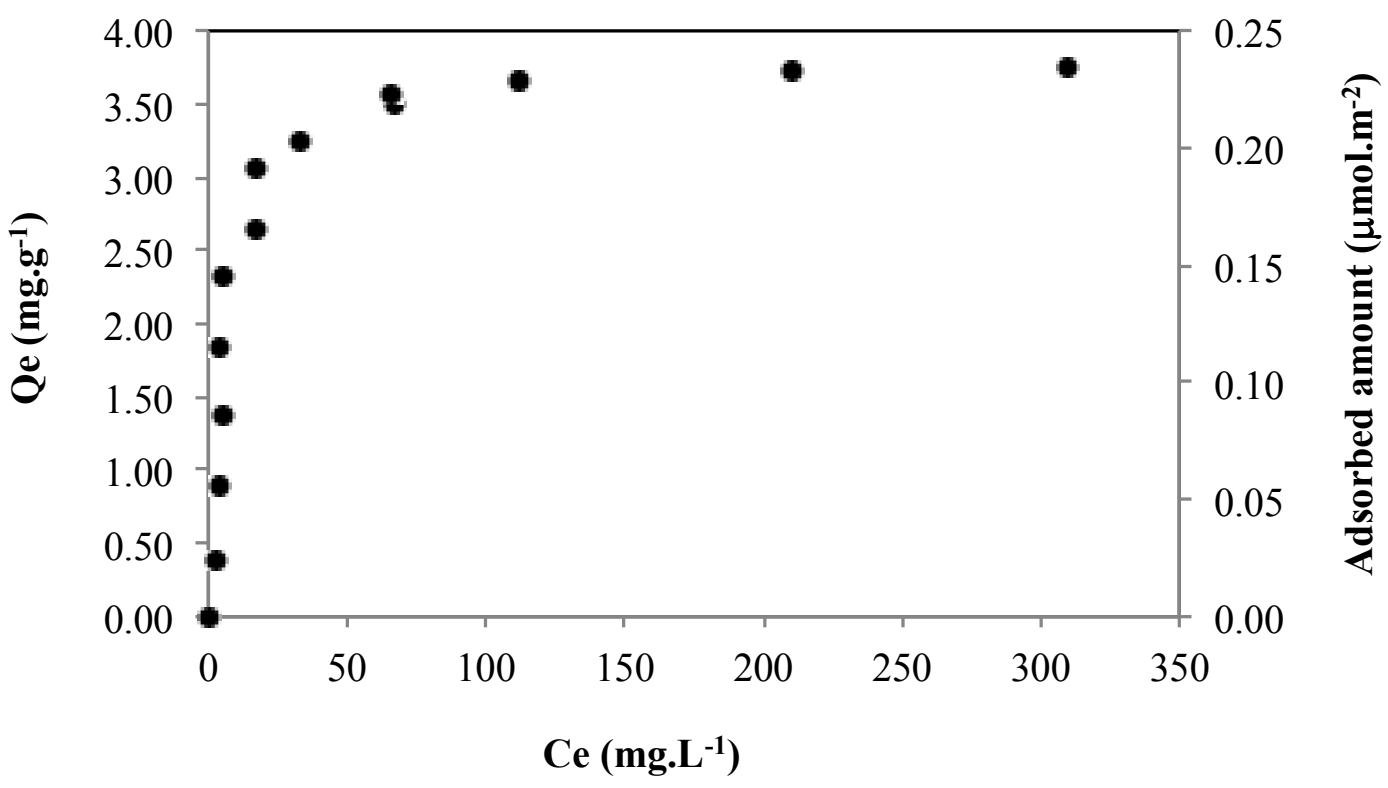

Figure 2. Adsorption isotherm of $\mathrm{ADIBA}$ onto the silica sol at $25^{\circ} \mathrm{C}$ and $\mathrm{pH}=9.1$. The experimental data are well fitted by the Langmuir adsorption model with a high correlation coefficient. The linearized form of the isotherm is shown in the Supporting Information (Figure $\mathrm{S} 3) .\left[\mathrm{SiO}_{2}\right]=50 \mathrm{~g} \cdot \mathrm{L}^{-1}$. 
As shown in the Supporting Information (Figure S3), the experimental data are well fitted by the Langmuir isotherm model. The maximal adsorption capacity $\left(4 \mathrm{mg} \cdot \mathrm{g}^{-1}\right.$ which equates to 0.25 $\mu \mathrm{mol} . \mathrm{m}^{-2}$ ) is in good agreement with the value of $3.5 \mathrm{mg} \cdot \mathrm{g}^{-1}$ reported by Schmid et al. ${ }^{39}$ for AIBA adsorption on an alcoholic silica sol and is slightly higher than the one determined by Luna-Xavier et al..$^{37}$ for an aqueous ammoniacal silica sol (Klebosol ${ }^{\circledR} 30 \mathrm{~N} 50,68 \mathrm{~nm}$ in diameter) similar to the one used in this study. This last result is consistent with the above-mentioned AIBA hydrolysis in basic media.

For all the emulsion experiments detailed in Tables 2 and 3 and that will be discussed later in the text, a fixed initiator concentration of $0.1 \mathrm{~g} . \mathrm{L}^{-1}$ was used, while the silica concentration was varied. This optimal amount of initiator was determined by plotting in Figure 3 the sorption data of ADIBA onto silica (for the three silica concentrations studied) as the adsorbed amount and the ADIBA equilibrium concentration (free ADIBA) against the initial ADIBA concentration. The results are summarized in Table 4 for an initial ADIBA concentration of 0.1 g.L $\mathrm{L}^{-1}$. Figure 3 and Table 4 clearly show that for a fixed initial ADIBA concentration of 0.1 g.L $\mathrm{L}^{-1}$ (see the red dotted line), the higher the silica concentration, the less ADIBA is adsorbed, but also the less remains free in the water phase. Under these conditions, we calculated that for experiments performed at 10 g. $\mathrm{L}^{-1}$ silica, the inorganic surface was completely coated with ADIBA and there was excess initiator in water, while for experiments performed at concentrations higher than 30 g. $\mathrm{L}^{-1}$, the surface was only partially covered and there was almost no excess ADIBA in water. In addition, zeta potential measurements of the silica particles before and after ADIBA adsorption indicated a reduction of the surface potential. As expected, the higher the adsorbed amount, the lower the absolute value of zeta potential (data not shown). 


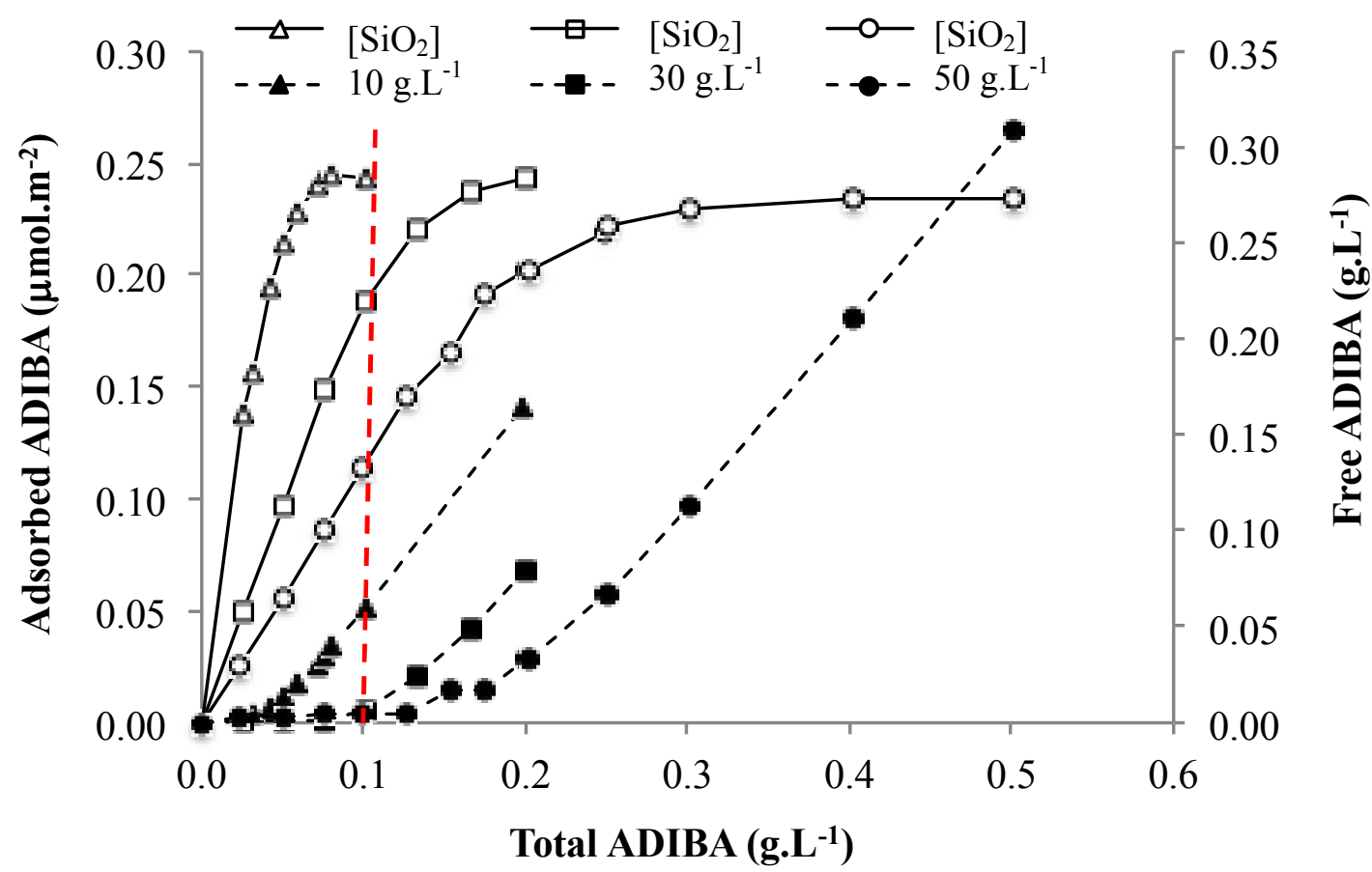

Figure 3. Langmuir isotherm data plotted as the amount of adsorbed ADIBA against its initial concentration in water (open symbols) for silica concentrations of 10,30 and 50 g.L $\mathrm{L}^{-1}$, respectively. The filled symbols represent the evolution of the ADIBA equilibrium concentration in water as a function of the initial ADIBA concentration.

Table 4. Adsorbed amounts and equilibrium ADIBA concentrations for different silica concentrations and a fixed ADIBA concentration of 0.1 g. $\mathrm{L}^{-1}$.

\begin{tabular}{|c|c|c|c|}
\hline$\left[\mathrm{SiO}_{2}\right]\left(\mathrm{g} . \mathrm{L}^{-1}\right)$ & $\mathrm{Ce}\left(\mathrm{mg} . \mathrm{L}^{-1}\right)$ & Qe $\left(\mathrm{mg.g}^{-1}\right)$ & Adsorbed amount $\left(\mu \mathrm{mol} . \mathrm{m}^{-2}\right)$ \\
\hline 10 & 60.2 & 4.0 & 0.25 \\
\hline 30 & 6.6 & 3.1 & 0.19 \\
\hline 50 & 4.5 & 1.9 & 0.11 \\
\hline
\end{tabular}

ADIBA adsorption has also a great impact on the silica particle size. Figure 4a shows the evolution of the silica particle diameter determined by DLS as a function of the initial ADIBA 
concentration for varying silica concentrations. The data are also plotted in Figure $4 \mathrm{~b}$ as a function of the adsorbed amount expressed in $\mu$ mol. $\mathrm{m}^{-2}$. Figure 4a shows that the silica particle size increases with increasing ADIBA concentration leading to the destabilization of the suspension for too high concentrations. The effect occurs at lower ADIBA concentrations for 10 g. $\mathrm{L}^{-1}$ than for 30 and 50 g. $\mathrm{L}^{-1}$ as the adsorbed amount increases with decreasing the silica concentration. Moreover, for a fixed adsorbed amount, Figure $4 \mathrm{~b}$ shows that, as expected, the higher the silica concentration, the greater the extent of aggregation. Therefore, in order to preserve colloidal stability of the silica sol and to avoid aggregation whatever the initial silica content, the initiator concentration was fixed to 0.1 g. $\mathrm{L}^{-1}$ for the rest of the study.

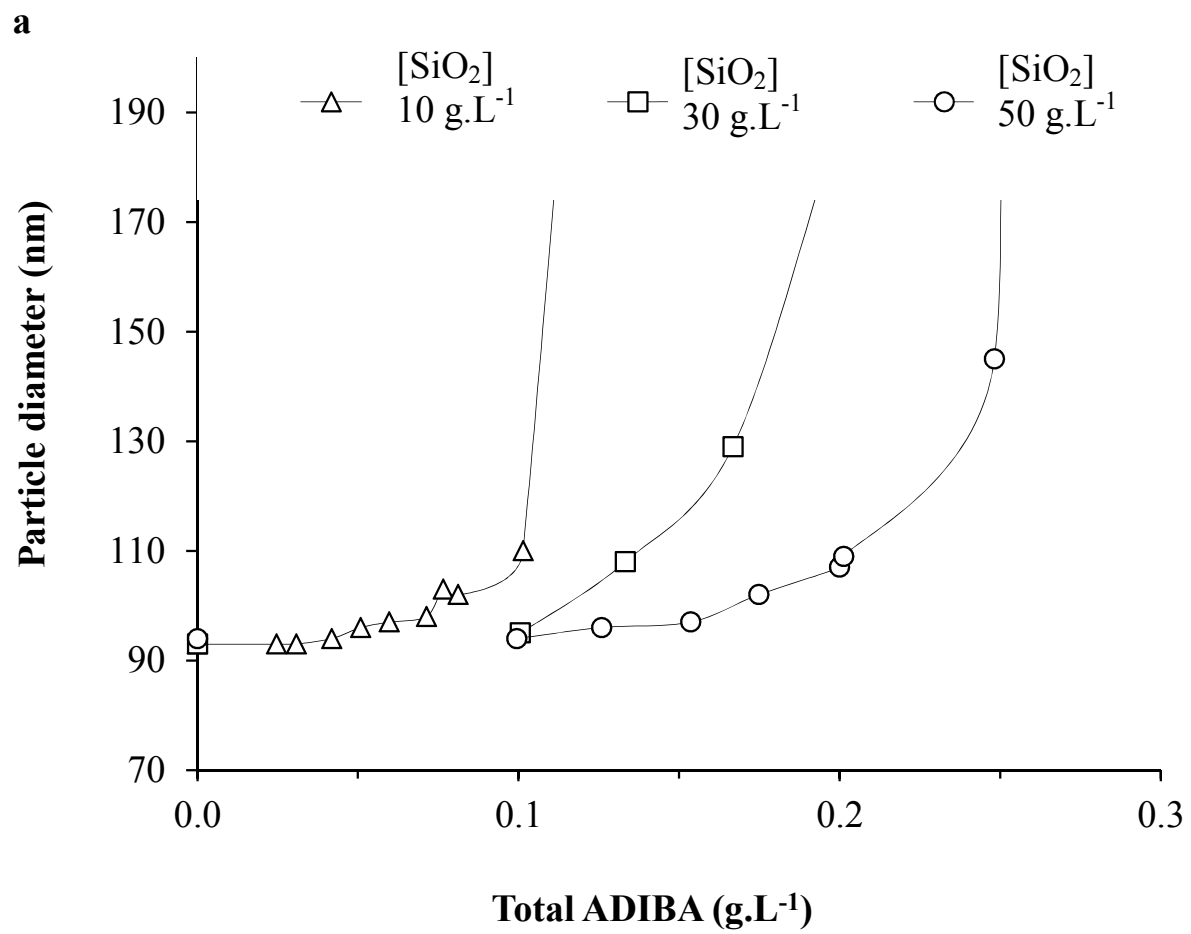

ACS Paragon Plus Environment 


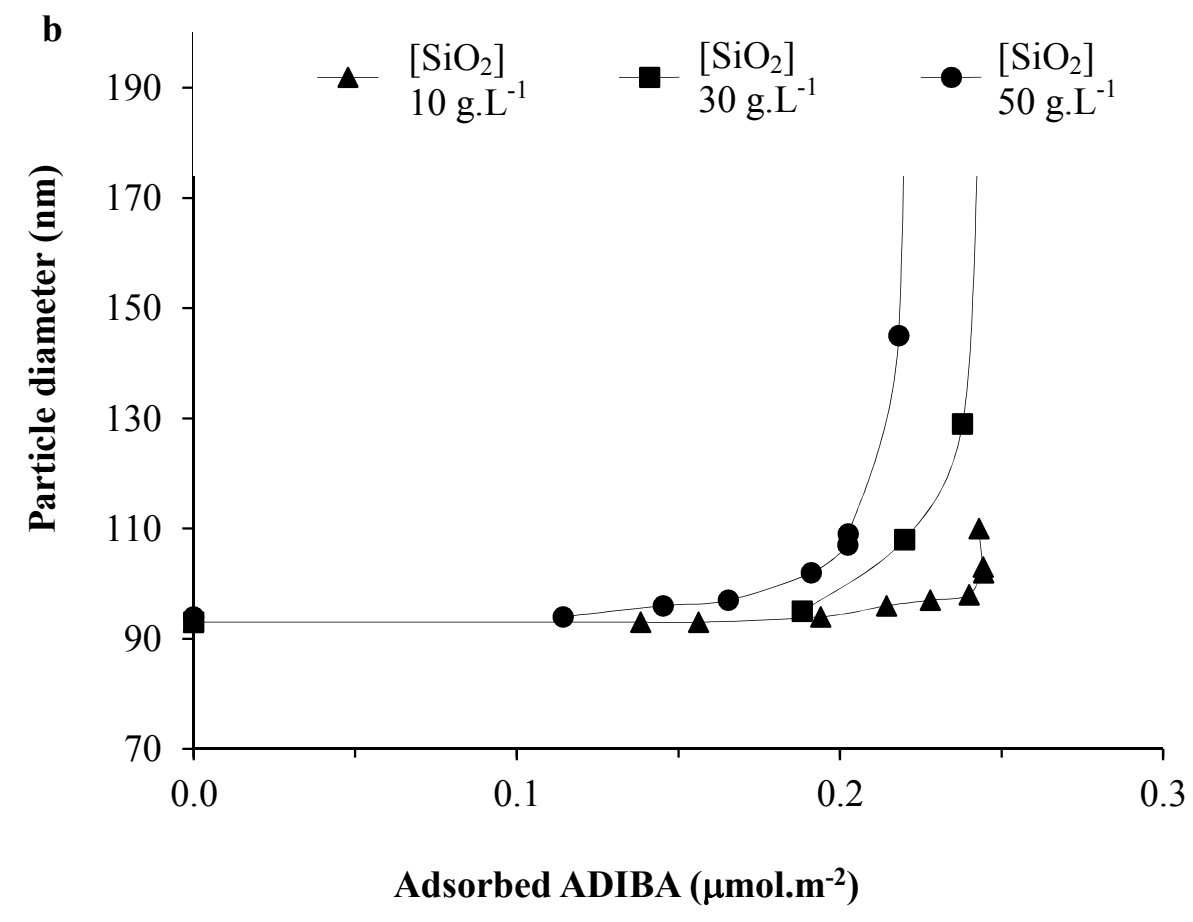

Figure 4. Effect of ADIBA adsorption on colloidal stability of the silica sol. The silica particle diameter is plotted against: a) the overall initial ADIBA concentration in water, and b) the ADIBA adsorbed amount $\left(\mu \mathrm{mol} . \mathrm{m}^{-2}\right)$ for various silica concentrations.

\section{Control of particle morphology and latex colloidal stability}

Effect of the nature of the surfactant. Non-ionic surfactants like NP30 are known to strongly adsorb onto silica, ${ }^{50}$ and strongly affect the morphology of the resulting composite latex particles by promoting monomer adsolubilization at the interface ${ }^{51}$ and enhancing the surface reactivity and wettability. ${ }^{37-38}$ A first experiment was therefore conducted in the presence of NP30 (3 g.L $\left.{ }^{-1}\right)$ as surfactant and 50 g.L. $\mathrm{L}^{-1}$ of silica (entry 3 in Table 2). Unfortunately, the latex was unstable, i.e. coagulated. As there was almost no free ADIBA initiator in water for this particular experiment 
(see Figure 3 and Table 4), and considering that the bicationic initiator is anchored by both ends (no initiator fragment can escape the silica surface), ${ }^{52}$ colloidal stability was only ensured by the non-ionic surfactant. The silica particles can also potentially contribute to the stabilization but, as shown in Figure 5, NP30 adsorption screens the silica surface charges leading in a reduction of zeta potential from -71.4 to $-54 \mathrm{mV}$. The surface charge density of the silica particles was therefore not sufficient to maintain the colloidal stability of the nucleated non-ionic latex particles. All above assumptions are supported by the fact that a stable latex with an average particle diameter of $215 \mathrm{~nm}$ and a zeta potential of $+30 \mathrm{mV}$ was produced when the polymerization was performed under identical conditions in the absence of silica particles, pointing out the specificity of the mechanism of particle formation in the present system involving a surface-anchored initiator.

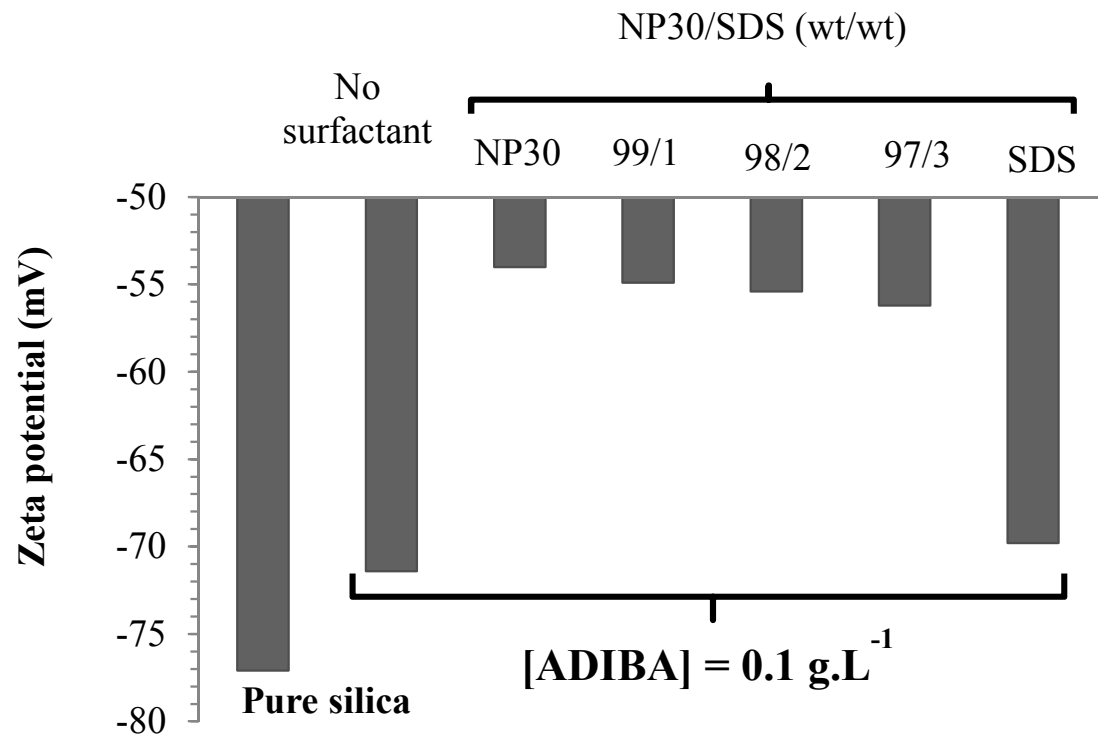

Figure 5. Electrophoretic measurements of the aqueous silica sol before ADIBA adsorption, after ADIBA adsorption $\left([\right.$ ADIBA $]=0.1$ g. $\left.\mathrm{L}^{-1}\right)$, and after adsorption and addition of NP30/SDS mixtures of various compositions. [Silica $]=50 \mathrm{~g} \cdot \mathrm{L}^{-1} \cdot \mathrm{pH}=9.1$. 
In order to stabilize the composite latex suspension, we therefore introduced a small amount of an anionic surfactant (SDS). Under such conditions, the latex stability was greatly improved. Mixtures of anionic and non-ionic surfactants are widely used in industry due to their favorable synergetic interaction. ${ }^{53-55}$ The anionic surfactant controls the particle nucleation stage, and the non-ionic surfactant imparts additional electrolyte tolerance, mechanical shear stability and freeze-thaw stability. In the present system, the addition of SDS provided additional stability to both the silica (see the evolution of zeta potential in Figure 5) and composite particles. As shown in Table 2, at least $2 \mathrm{wt} \%$ of SDS (based on the total amount of surfactant, NP30/SDS $=98 / 2$ $\mathrm{wt} / \mathrm{wt}$ and $[\mathrm{SDS}]=0.06 \mathrm{~g} \cdot \mathrm{L}^{-1}$ ) was necessary to stabilize the latex particles and reach full conversions. As shown in Figure S4 (Supporting Information) and Table 2 (entries 2 and 5), increasing the surfactant concentration from 2 to $3 \mathrm{wt} \%$ (NP30/SDS $=97 / 3 \mathrm{wt} / \mathrm{wt}$ ) had no major effect on particle morphology (i.e., the $\mathrm{N}_{\text {Latex }} / \mathrm{N}_{\text {Silica }}$ ratio was close to one in both cases) suggesting that the number of nucleated latex particles was not influenced by the amount of surfactant in this range of concentrations. However, increasing further the SDS concentration led to a complete loss of particle morphology (Figure 6). Indeed, when SDS was used as sole surfactant under experimental conditions leading to $\mathrm{N}_{\text {Latex }} / \mathrm{N}_{\text {Silica }}=1.05\left(\left[\mathrm{SiO}_{2}\right]=110\right.$ g.L $\mathrm{L}^{-1}$, entry 6 in Table 2), TEM revealed the formation of a large number of free latex particles together with isolated silica particles and a few dimers. Therefore, in the next section, the amount of SDS was fixed to $2 \mathrm{wt} \%$ (NP30/SDS $=98 / 2 \mathrm{wt} / \mathrm{wt}$ ) to ensure the successful formation of composite particles and maintain the colloidal stability of the system. 


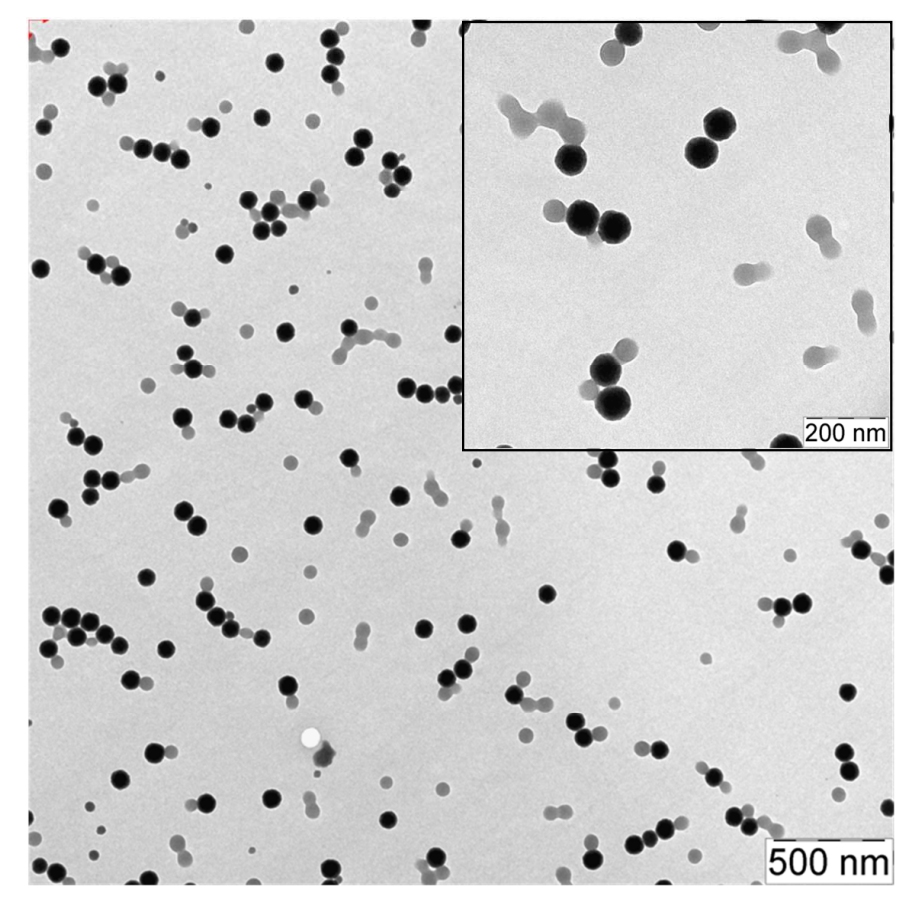

Figure 6. TEM images of hybrid latex particles obtained in the presence of pure SDS for $\left[\mathrm{SiO}_{2}\right]$ $=110 \mathrm{~g} \cdot \mathrm{L}^{-1}$ showing separate populations of silica and polymer particles (entry 6 in Table 2).

Effect of the silica concentration. In this section, we investigated the effect of the silica concentration on the $\mathrm{N}_{\text {Latex }} / \mathrm{N}_{\text {Silica }}$ ratio and the particle morphology. Any other parameter was kept constant and only the silica concentration was varied (entries 2 and 7-10 in Table 2). As previously mentioned, the amount of SDS was fixed at $2 \mathrm{wt} \%(\mathrm{NP} 30 / \mathrm{SDS}=98 / 2 \mathrm{wt} / \mathrm{wt})$. At first sight, the findings in Table 2 were as expected if one assumes a constant number of nucleated latex particles: the $\mathrm{N}_{\text {Latex }} / \mathrm{N}_{\text {Silica }}$ ratio decreased with increasing the silica concentration. For the lowest silica concentration (i.e. 10 g. $\mathrm{L}^{-1}$ ), TEM analysis revealed the formation of hybrid latexes characterized by in average 3 polymer nodules bound to one silica particle (Figure S5, Supporting Information). Free latex particles could also be clearly identified in the TEM images. These particles likely result from initiation and propagation reactions in the continuous phase 
owing to the presence of free initiator. For a silica concentration of 90 g. $\mathrm{L}^{-1}$, the number of nucleated polymer nodules was on the contrary lower than the silica particles number, and some latex particles shared two silica beads. Optimized results were therefore obtained for intermediate concentrations $\left(\left[\mathrm{SiO}_{2}\right]=40-50 \mathrm{~g} \cdot \mathrm{L}^{-1}\right)$. In fact, a closer look at the data in Table 2 reveals that the number of PMMA particles is not constant, but depends on the amount of silica introduced in the reactor indicating that the silica seeds also contribute to the stabilization of the growing polymer nodules as already reported in the literature for related systems. ${ }^{56,57}$ Therefore, the optimum morphology could not be predicted by simply adjusting the number of silica particles such as to get a one-to-one ratio, and required trial and error investigations.

In order to provide a more reliable analysis of particle morphology under optimized conditions (i.e. for $\left[\mathrm{SiO}_{2}\right]=40$ and 50 g. $\mathrm{L}^{-1}$ ), the hybrid particles were observed by cryo-TEM in their hydrated environment (Figure 7). Provided that the suspension was sufficiently diluted, one could observe a majority of isolated dumbbell-shaped particles. Some hybrid structures resulting from the growth of two latex particles on one silica seed (so-called "trimers") could also be seen together with very few tetramers (one silica surrounded by three polymer nodules) and isolated silica particles. Note that the presence of the tetramers could not be assessed with certainty due to the fact that the hybrid particles have a strong tendency to stick to each other on the TEM grid (Figure S6, Supporting Information). A statistical analysis based on 200 particles gave nonetheless $62 \%$ dimers, $15 \%$ trimers, $2 \%$ tetramers and $21 \%$ isolated silica spheres for $\left[\mathrm{SiO}_{2}\right]$ $=40 \mathrm{~g} \cdot \mathrm{L}^{-1}$. 


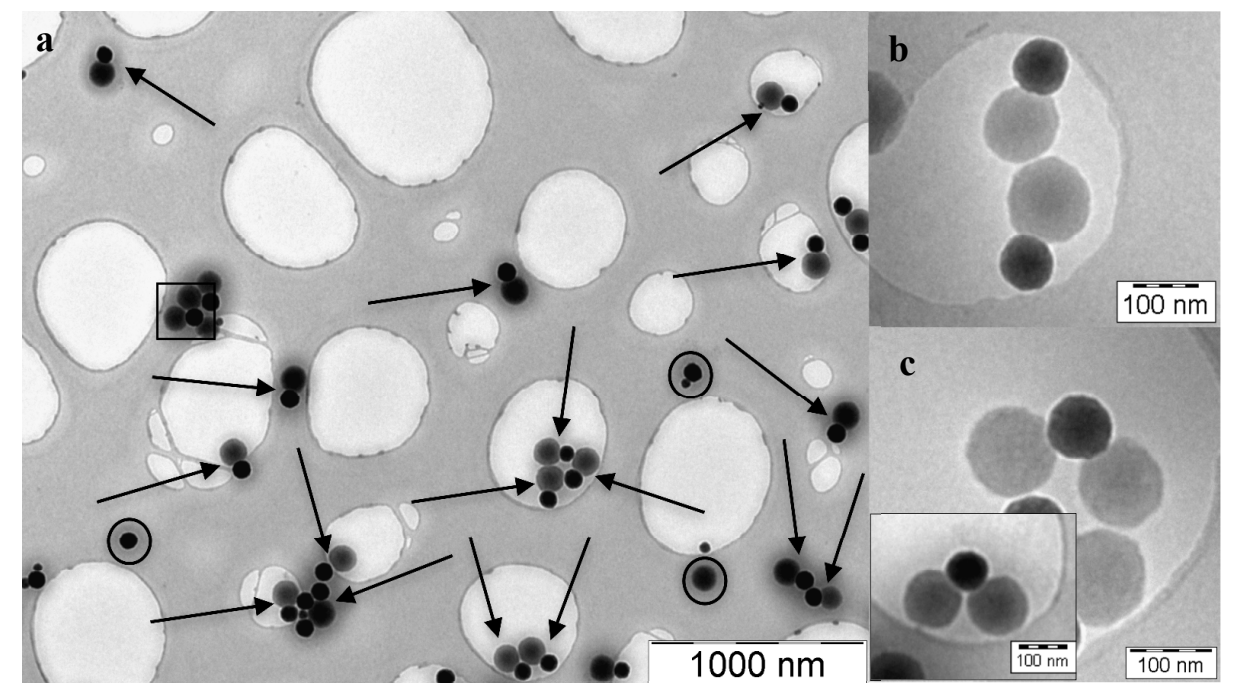

Figure 7. Cryo-TEM images of: a) dissymmetrical silica/PMMA heterodimers with a $\mathrm{N}_{\text {Latex }} / \mathrm{N}_{\text {Silica }}$ ratio of 0.95 (monomer conversion $=92 \%$ ) showing the presence of dumbbellshaped particles (arrows), trimers (squares) and isolated silica (circles). b) and c) correspond to an enlarge view of respectively the dumbbell and trimer particles. $\left[\mathrm{SiO}_{2}\right]=40 \mathrm{~g} . \mathrm{L}^{-1}$ and NP30/SDS $=98 / 2(\mathrm{wt} / \mathrm{wt})$ (entry 9 in Table 2$).$

"Trimer" heterostructures similar to the ones shown in Figure 7c were also reported by Perro et $a l{ }^{36}$ during the synthesis of dumbbell-shaped silica/PS colloids through emulsion polymerization using an oxyethylene-based macromonomer as compatibilizing agent. Although such particles have a relatively low probability of occurrence, they cannot be completely avoided for statistical reasons. The free silica particles are likely the direct consequence of the surface-initiation mechanism. In free radical polymerization, the rate of initiation depends on the half-life of the initiator (ADIBA has a 10 hour half-life decomposition temperature of $44^{\circ} \mathrm{C}$ in water) and the efficiency factor (only a fraction of radicals produced can effectively initiate the polymerization). It was demonstrated that surface-anchored initiators have lower initiation efficiency than free 
radicals in solution due to the high probability of the tethered radicals to undergo termination reactions. ${ }^{58}$ In addition, it was shown that the half-life of AIBA adsorbed on mica was also lower than that of the same compound in solution. ${ }^{49}$ Initiator destabilization was attributed to "ring tension" and was found to be more important when the initiator was bound at both ends than at just one end. ${ }^{59}$ "Ring" referred in this case to the structure formed by the initiator adsorbed onto the inorganic surface. Taking all these aspects into consideration, the half-life and radical efficiency of ADIBA may not only depend on whether it is adsorbed or not but also on the chemical and steric characteristics of the surface sites on which it is adsorbed. Therefore, it is possible that the silica particles have different initiation rates due to different local conformations of adsorbed ADIBA molecules resulting in different half-lives and efficiency factors. This would result in some particles being more active than some others. Furthermore, radicals being continuously generated in the system, some silica particles may also simply initiate polymer chain growth earlier than some others resulting in a fraction of particles being unable to initiate the polymerization as the initiator concentration decreases. To conclude, although it is likely that the radical efficiency is decreased in the present system resulting in a fraction of inactive silica, it is apparently high enough to allow the formation of polymer particles with complete monomer conversions.

\section{Evolution of particle morphology with time}

In order to gain deeper insight into the mechanism of dissymmetric particle formation, the morphological evolution of the PMMA/silica heterodimers with monomer conversion was studied. The silica concentration was fixed at 40 g.L. $\mathrm{L}^{-1}$. Figure 8 shows some representative cryoTEM images. Enlarged views can be found in the Supporting Information (Figure S7). 


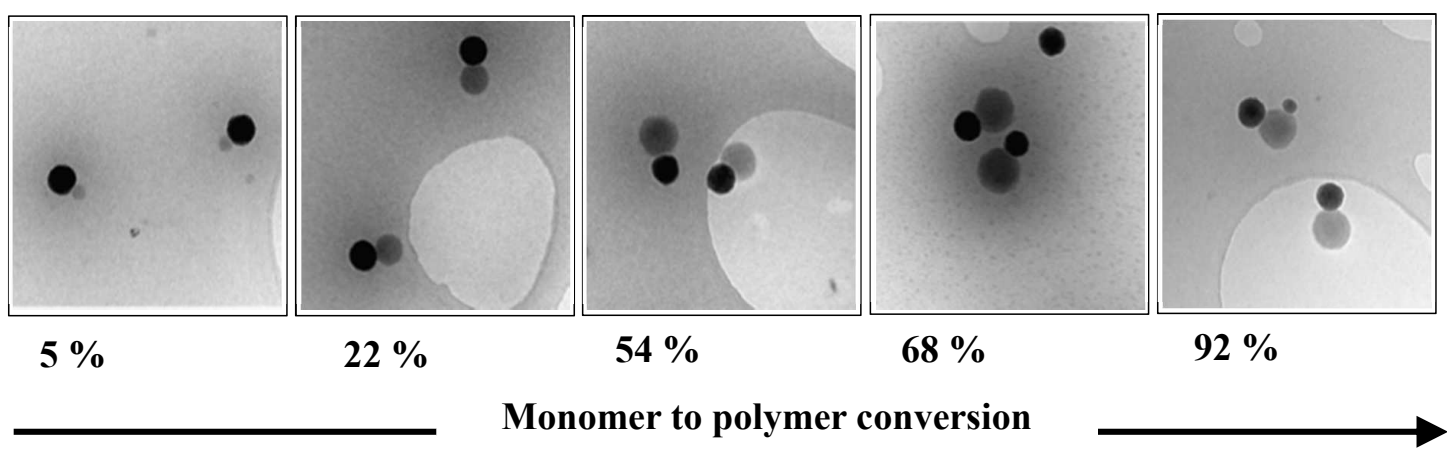

Figure 8. Evolution of particle morphology with conversion during the synthesis of dissymmetrical silica/PMMA heterodimers. $\left[\mathrm{SiO}_{2}\right]=40$ g. $\mathrm{L}^{-1}$ and NP30/SDS $=98 / 2(\mathrm{wt} / \mathrm{wt})$ (entry 10 in Table 2).

The cryo-TEM images were statistically analyzed to determine the diameter of the PMMA nodules and the $\mathrm{N}_{\text {Latex }} / \mathrm{N}_{\text {Silica }}$ ratio (Table 5).

Table 5. Evolution of the monomer conversion and diameter of the growing PMMA nodules with time during the synthesis of silica/PMMA dissymmetrical particles. $\left[\mathrm{SiO}_{2}\right]=40 \mathrm{~g} \cdot \mathrm{L}^{-1}$ and NP30/SDS $=98 / 2(\mathrm{wt} / \mathrm{wt})($ entry 10 in Table 2$)$.

\begin{tabular}{llllll}
\hline Time (min) & Conversion $(\%)$ & $\mathbf{D}_{\mathbf{n} \text { Latex }}(\mathbf{n m})$ & $\mathbf{D}_{\mathbf{w}} / \mathbf{D}_{\mathbf{n}}$ & $\mathbf{N}_{\text {Latex }} / \mathbf{N}_{\text {Silica }}{ }^{a}$ & $\mathbf{N}_{\text {Latex }} / \mathbf{N}_{\text {Silica }} \mathbf{b}$ \\
\hline 9 & 5 & 56 & 1.07 & 0.69 & 0.54 \\
20 & 22 & 91 & 1.04 & 0.76 & 0.57 \\
35 & 54 & 113 & 1.06 & 0.80 & 0.71 \\
40 & 68 & 115 & 1.07 & 0.82 & 0.85 \\
85 & 92 & 125 & 1.03 & 0.95 & 0.88 \\
\hline
\end{tabular}

${ }^{a}$ Determined by counting manually in the TEM images the number of latex and silica particles.

${ }^{b}$ Determined using equation (3) from the diameters of the silica and PMMA latex particles measured by TEM. Note the good agreement between the two methods. 
In agreement with Figure 8, the diameter of the PMMA nodules increased with increasing conversion. Consequently, snowman- and reverse snowman-like dimers were mainly produced at very low and high conversions (silica being the largest nodule at low conversion and the smallest one at high conversion) while particles with a dumbbell-like morphology (the silica and PMMA particles having more or less the same size) were observed at around $22 \%$ of conversion. Interestingly enough, the $\mathrm{N}_{\text {Latex }} / \mathrm{N}_{\text {Silica }}$ ratio (determined by either of the two methods described in the experimental section) also increased with increasing monomer conversion indicating a prolonged nucleation period up to around $70 \%$ of monomer conversion. In emulsion polymerization, prolonged nucleation is usually observed when the generation rate of radicals is very low which is likely the case in the present system. However, one may argue that this should result in broadening of the particle size distribution, which was not observed experimentally. In fact, Vanderhoff and co-workers studied the competitive growth of latex particles during emulsion polymerization and demonstrated that small particles grow faster than larger ones if their size is lower than typically $150 \mathrm{~nm}$ resulting in a narrowing of the particle size distribution. ${ }^{60}$ This point also raises the important question of the mechanism of particle nucleation and growth in the present system. Polymer chains are undoubtfully initiated at the silica surface resulting in the formation of polymer domains whose sizes (and therefore numbers) are determined by the amount of surfactant available for their stabilization. The fact that it is possible to nucleate a single polymer nodule although there are multiple initiation sites on the surface suggests that the growing chains can diffuse and coalesce to minimize the interfacial energy. The monomer-swollen polymer particles then grow like in conventional emulsion polymerization, by capturing free radicals formed in the water phase. However, here, one may wonder whether the low amount of free non-adsorbed initiator is sufficient to ensure polymer 
chains growth in water. It is possible that some initiator molecules desorb from the silica surface during polymerization to maintain thermodynamic equilibrium as the free initiator is consumed, which would guarantee the production of aqueous phase radicals all long during polymerization. These questions as well as the implication they may have on the kinetics and mechanism of this new surface-initiated emulsion polymerization process will be addressed in future studies.

The evolution of particle morphology with time was further investigated by SAXS. The scattering by suspensions of dimers for increasing MMA conversions and 50 g. $\mathrm{L}^{-1}$ silica is plotted in Figure 9. Starting from a conversion of $4 \%$, the data are shifted for clarity.

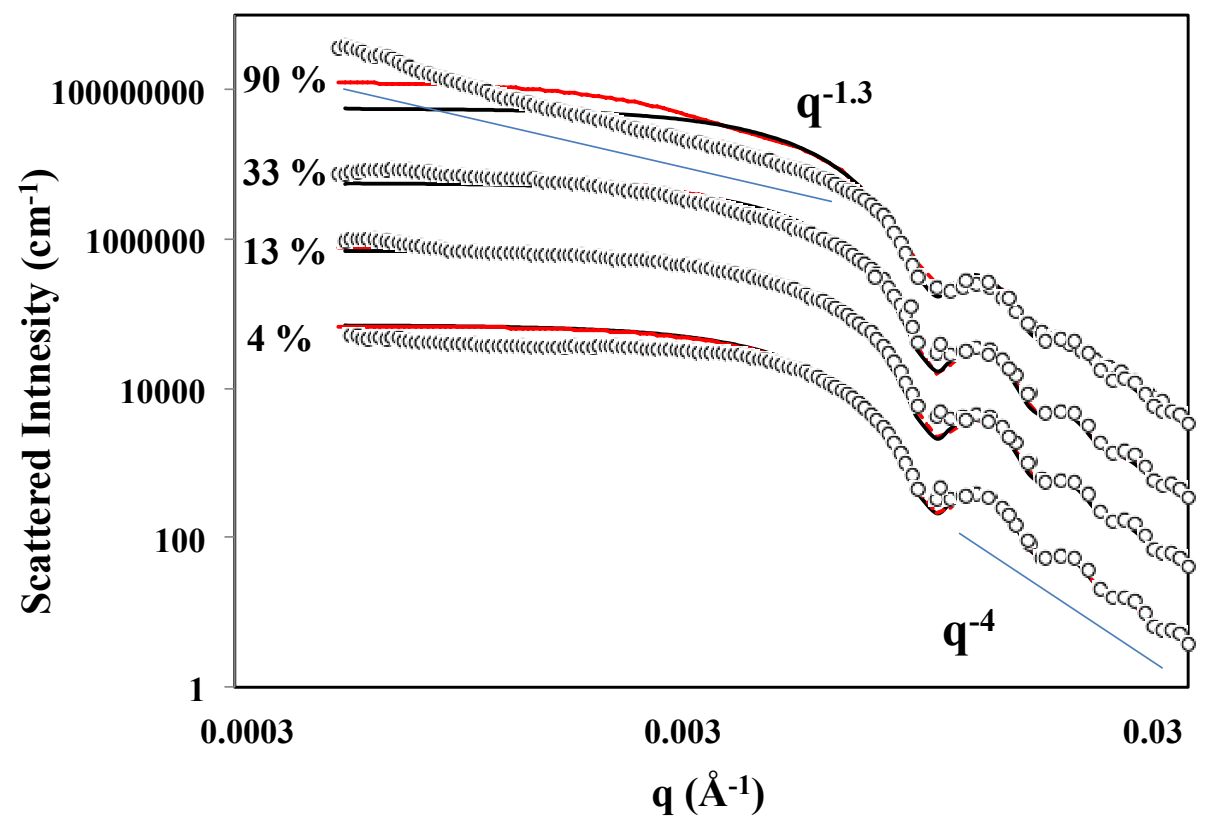

Figure 9. I(q) versus $\mathrm{q}$ plots during the synthesis of silica/PMMA dissymmetrical latex particles. The full lines in black are the predicted scattering intensity of the silica spheres while the dotted lines in red correspond to that of the silica/PMMA heterodimers. $\left[\mathrm{SiO}_{2}\right]=50$ g.L $\mathrm{L}^{-1}$ and NP30/SDS $=98 / 2($ entry 2 in Table 2$)$. 
For each conversion, the theoretical scattering of the pristine silica dispersion is shown together with the scattering by a suspension of dimers corresponding to this particular conversion. All the diagrams display a $\mathrm{q}^{-4}$ decrease in intensity at large $\mathrm{q}$. This is the signature of an abrupt interface between the surface of the objects (both silica and PMMA spheres) and the solvent. There is also an oscillation of the signal that allows the measurement of the size of the objects. The diameter of silica is the same for all the samples, but the diameter of the latex beads $\mathrm{D}_{\text {Latex }}$ is increasing with conversion. There is no direct signature of the latex diameter in the scattering pattern because of their low contribution due to their low scattering contrast with the solvent. However, assuming that all the objects are dimers made of a latex bead attached to a silica bead, the diameter of the latex bead can be calculated in such a way that the conversion is respected. Indeed, the small angle scattering of a dimer object made of two spheres in direct contact, with scattering length density $\rho_{\text {Silica }}$ and $\rho_{P M M A}$ is given by:

$$
\begin{aligned}
& I(q)=\left(\rho_{\text {Silica }}-\rho_{w}\right)^{2} V_{\text {Silica }}^{2} f^{2}\left(q D_{\text {Silica }}\right)+\left(\rho_{\text {latex }}-\rho_{w}\right)^{2} V_{\text {latex }}^{2} f^{2}\left(q D_{\text {latex }}\right) \\
& +2\left(\rho_{\text {Silica }}-\rho_{w}\right)\left(\rho_{\text {latex }}-\rho_{w}\right) V_{\text {Silica }} f\left(q D_{\text {Silica }}\right) V_{\text {latex }} f\left(q D_{\text {latex }}\right) \frac{\sin \left(q\left(D_{\text {Silica }}+D_{\text {latex }}\right) / 2\right)}{q\left(D_{\text {Silica }}+D_{\text {latex }}\right) / 2}
\end{aligned}
$$

in which the amplitude scattering factor of one sphere $f(q D)$ is :

$$
f(q D)=3 \frac{\sin (q D / 2)-q D / 2 \cos (q D / 2)}{(q D / 2)^{3}}
$$

The scattering length density of water is $\rho_{w}=9.4310^{11} \mathrm{~cm}^{-2}$. Considering a mass density of 2 g. $\mathrm{cm}^{-3}$ for silica and $1.20 \mathrm{~g} . \mathrm{cm}^{-3}$ for PMMA, their scattering length densities are $\rho_{\text {Silica }}=1.7510^{11} \mathrm{~cm}^{-2}$ and $\rho_{\text {latex }}=1.110^{11} \mathrm{~cm}^{-2}$, respectively.

As shown in Figure 9, in the case of a low conversion (4\%), the theoretical signal of the corresponding dissymmetrical particle is almost equal to the theoretical signal of the silica bead 
in the whole range of q. In particular at large q, the fitting of the oscillations allows to determine the size distribution of the silica beads. A fit by a Gaussian distribution of spheres yields to $\mathrm{D}_{\text {Silica }}$ $=81 \pm 4 \mathrm{~nm}$ which is in good agreement with the diameter determined by TEM. Given the silica particles size, one can then calculate the diameters of the latex beads for a given conversion using equation (5). The results are reported in Table 6.

Table 6. Evolution of the diameter of the PMMA nodules with monomer conversion as determined by SAXS analysis. $\left[\mathrm{SiO}_{2}\right]=50 \mathrm{~g} \cdot \mathrm{L}^{-1}$ and NP30/SDS $=98 / 2$ (entry 2 in Table 2).

\begin{tabular}{lcccc}
\hline Monomer to polymer conversion (\%) & 4 & 13 & 33 & 90 \\
\hline $\mathrm{D}_{\text {Latex }}(\mathrm{nm})$ & 43 & 64 & 87 & 121 \\
\hline $\mathrm{D}_{\text {Silica }}(\mathrm{nm})=81 \pm 4$ & & &
\end{tabular}

Equation (5) only holds when the interactions between the objects can be neglected. The use of a silica concentration of 50 g. $\mathrm{L}^{-1}$ was mandatory to obtain a good signal in the USAXS region. Under such conditions (volume fraction equals $2.1 \%$ ), electrostatic interaction drives the particles in slight interaction. Indeed, in Figure 9, the theoretical intensity calculated for 4\% conversion is above the experimental data revealing repulsive interaction between the dissymmetrical particles. When the conversion increases (13\% and 33\%), the theoretical curves are closer to the experimental ones. This reveals that the repulsions between the dissymmetrical particles decrease. However, the incomplete match of the theoretical curves with the experimental ones allows concluding that the particles have the correct mass (agreement of intensities at very low q), but one cannot firmly conclude that the particles have a dimer shape. The situation at $90 \%$ of conversion is different. Indeed, the scattering at low angle is strongly increasing like $\mathrm{q}^{-1.3}$ without saturation. This means that linear chains are formed whose size is 
much beyond the resolution of the camera $(600 \mathrm{~nm})$. These large objects are certainly to be related to the poor long-term stability of the latex suspension mentioned earlier as no extra surfactant was added in these experiments. Again, in that case, the dimer aspect of the units forming these aggregates cannot be ascertained.

\section{Silica/polystyrene heterodimer particles}

To assess the versatility and robustness of the method, the process was extrapolated to styrene (Table 3). Again, a trial and error approach was used to find the best conditions leading to high yields of heterodimer particles. As shown in Table 3 and Figure 10, optimized morphologies could be obtained for $\left[\mathrm{SiO}_{2}\right]=50 \mathrm{~g} \cdot \mathrm{L}^{-1}$ and $1 \mathrm{wt} \% \mathrm{SDS}(\mathrm{NP} 30 / \mathrm{SDS}=99 / 1 \mathrm{wt} / \mathrm{wt})$. Again, snowman-like particles were formed at low conversion whereas the particles exhibited a dumbbell shape at higher conversions.

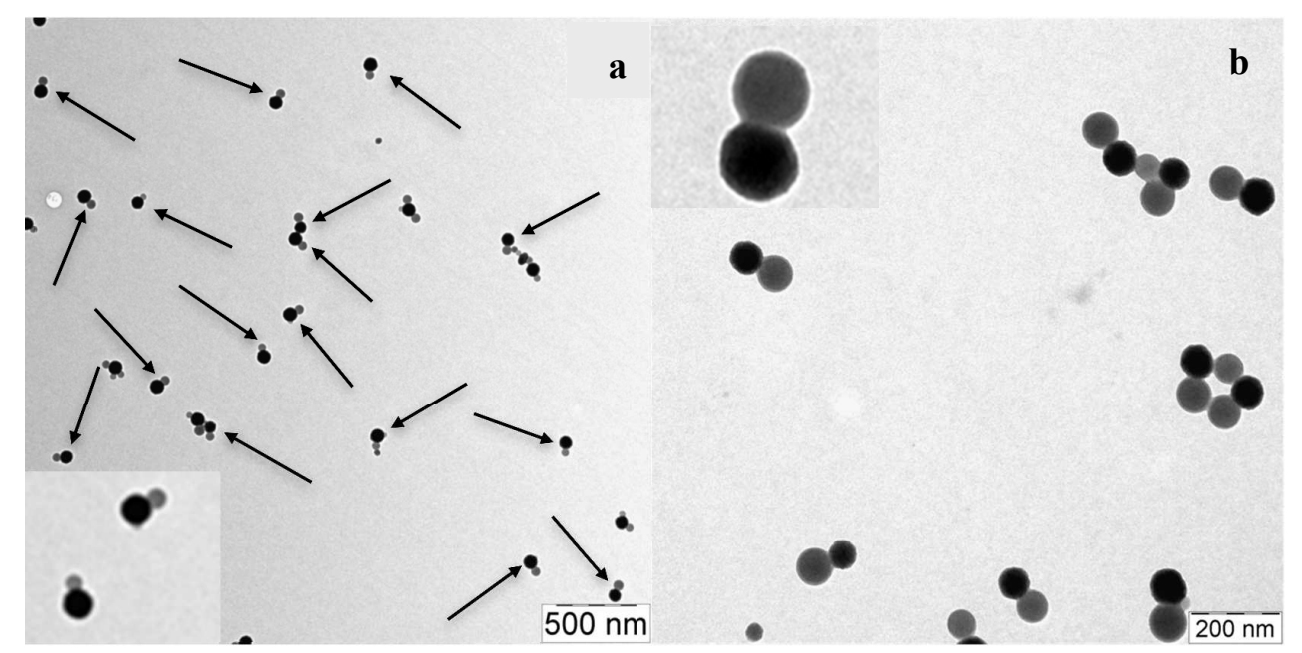

Figure 10. TEM images of dissymmetrical snowman-like (a) and dumbbell-like (b) silica/ polystyrene composite particles. a) $13 \%$ and b) $50 \%$ conversion. Arrows point to the dissymmetrical particles. $\left[\mathrm{SiO}_{2}\right]=50$ g.L $\mathrm{L}^{-1}$ and NP30/SDS $=99 / 1$ (entry 3 in Table 3). 


\section{CONCLUSIONS}

Anisotropic silica/PMMA particles with dissymmetrical snowman- and dumbbell-like morphologies were synthesized for the first time through batch emulsion polymerization using a surface-adsorbed cationic initiator. The success of the reaction relies on a number of parameters. First, the nature of the initiator is the key to successful formation of composite dissymmetrical particles. By combining a cationic azo initiator, ADIBA, with negatively charged silica particles, colloidally stable particles with one polymer module attached to a single silica sphere were obtained. The influence of various synthesis parameters has been investigated. First, the ADIBA concentration needs to be adjusted to a critical value of 0.1 g. $\mathrm{L}^{-1}$, above which the silica suspension starts aggregating. At this concentration, the silica surface is saturated with initiator molecules and excess ADIBA is present in water for silica contents lower than 30 g.L $\mathrm{L}^{-1}$. For higher silica contents, the surface is only partially covered with ADIBA and there is almost no excess initiator. The free radicals are therefore mainly produced at the silica surface, assuming that for such low surface coverage, ADIBA adsorbs by both extremities. This allowed initiation and nucleation to preferentially take place at the silica surface without the formation of free polymer. The use of a mixture of non-ionic and anionic surfactants was shown to be essential to ensure efficient colloidal stability of the nucleated polymer nodules and form heterodimer particles in high yield. At least $2 \mathrm{wt} \%$ SDS (relative to the total amount of surfactant, i.e., NP30 plus SDS) were necessary to stabilize the composite latex suspension. However, extra surfactant was added after polymerization to ensure long-term stability. The particle morphology evolved from snowman- to dumbbell-like depending on monomer conversion as confirmed by TEM and SAXS analysis. At last, the polymerization method was extended with success to styrene 
demonstrating the strength and high versatility of this new process in the production of silica/polymer dissymmetrical particles with snowman and dumbbell shapes.

\title{
SUPPORTING INFORMATION
}

Structures of the main chemicals used in the study. TEM image and particle size histogram of $\mathrm{Klebosol}^{\circledR} 30 \mathrm{~N} 50$. Linearized form of the Langmuir adsorption isotherm of ADIBA on the silica sol. TEM images illustrating the effects of the SDS and silica concentrations on particle morphology. Cryo-TEM images of dissymmetrical silica/PMMA heterodimers with a $\mathrm{N}_{\text {Latex }} / \mathrm{N}_{\text {Silica }}$ ratio close to one and evolution of particle morphology with monomer conversion. "This material is available free of charge via the Internet at http://pubs.acs.org."

\section{ACKNOWLEDGMENT}

The authors gratefully acknowledge financial support from the Agence Nationale pour la Recherche through the ToCoMo project (contract \# ANR-07-BLAN-0271).

\begin{abstract}
ABBREVIATIONS
MMA, methyl methacrylate; PMMA, poly(methyl methacrylate); PS, polystyrene; SDS, sodium dodecyl sulfate; VA86, 2,2'-azobis[2-methyl- $N$-(2-hydroxyethyl) propionamide]; ADIBA, 2,2'-azobis( $N, N$ '-dimethylene isobutyramidine) dihydro chloride; DLS, dynamic light scattering; TEM, transmission electron microscopy; cryo-TEM, cryogenic TEM; SAXS, small angle X-ray scattering; USAXS, ultra small angle X-ray scattering.
\end{abstract}

\section{REFERENCES}

(1) Bourgeat-Lami, E. J. Nanosci. Nanotechnol. 2002, 2, 1-24. 
(2) Bourgeat-Lami, E.; Lansalot, M. Adv. Polym. Sci. 2010, 233, 53-123.

(3) Sheridon, N. K.; Richley, E. A.; Mikkelsen, J. C.; Tsuda, D.; Crowley, J. M.; Oraha, K. A.; Howard, M. E.; Rodkin, M. A.; Swidler, R.; Sprague, R. J. Soc. Info. Display 1999, 7, $141-$ 144.

(4) Hosein, I. D.; Ghebrebrhan, M.; Joannopoulos, J. D.; Liddell, C. M. Langmuir 2010, 26, 2151-2159.

(5) Ngo, T. T.; Liddell, C. M.; Ghebrebrhan, M.; Joannopoulos, J. D. Appl. Phys. Lett. 2006, $88,241920-241923$.

(6) Li, F.; Josephson, D. P.; Stein, A. Angew. Chem. Int. Ed. 2011, 50, 360-388.

(7) Hu, S-H.; Gao, X. J. Am. Chem. Soc. 2010, 132, 7234-7237.

(8) Nakahama, K.; Kawaguchi, H.; Fujimoto, K. Langmuir 2000, 16, 7882-7886.

(9) Murthy, V. S.; Kadali, S. B.; Wong, M. S. ACS Appl. Mater. Interf. 2009, 1, 590-596.

(10) Binks, B. P.; Fletcher, P. D. I. Langmuir 2001, 17, 4708-4710.

(11) Takahara, Y. K.; Ikeda, S.; Ishino, S.; Tachi, K.; Ikeue, K.; Sakata, T.; Hasegawa, T.; Mori, H.; Matsumura, M.; Ohtani, B. J. Am. Chem. Soc. 2005, 127, 6271-6275.

(12) Kim, J-W.; Lee, D.; Shum, H. C.; Weitz, D. A. Adv. Mater. 2008, 20, 3239-3243.

(13) Walther, A.; Hoffmann, M.; Müller, A. H. E. Angew. Chem. Int. Ed. 2008, 47, 711-714.

(14) Qiang, W.; Wang, Y.; He, P.; Xu, H.; Gu, H.; Shi, D. Langmuir 2008, 24, 606-608.

(15) Yin, Y.; Lu, Y.; Gates, B.; Xia, Y. J. Am. Chem. Soc. 2001, 123, 8718-8729.

(16) Kim, J-W.; Larsen, R.J.; Weitz, D. A. Adv. Mater. 2007, 19, 2005-2009.

(17) Lu, W.; Chen, M.; Wu, L. J. Colloid Interf. Sci. 2008, 328, 98-102.

(18) Tang, C.; Zhang, C.; Liu, J.; Qu, X.; Li, J.; Yang, Z. Macromolecules 2010, 43, 5114-5120.

(19) Zhang, C.; Liu, B.; Tang, C.; Liu, J.; Qu, X.; Li, J.; Yang, Z. Chem. Commun. 2010, 46, 4610-4612.

(20) Teo, B. M.; Suh, S. K.; Hatton, T. A.; Ashokkumar, M.; Grieser, F. Langmuir 2011, 27, 3033.

(21) Ge, J.; Hu, Y.; Zhang, T.; Yin, Y. J. Am. Chem. Soc. 2007, 129, 8974-8975.

(22) Yin, Y.; Zhou, S.; You, B.; Wu, L. J. Polym. Sci. Part A: Polym. Chem. 2011, 49, 32723279 .

(23) Hong, L.; Jiang, S.; Granick, S. Langmuir 2006, 22, 9495-9499.

(24) Liu, B.; Wei, W.; Qu, X.; Yang, Z. Angew. Chem. Int. Ed. 2008, 47, 3973-3975. 
(25) Liu, B.; Zhang, C.; Liu, J.; Qu, X.; Yang, Z. Chem. Commun. 2009, 3871-3873.

(26) Pardhy, N. P.; Budhlall, B. M. Langmuir 2010, 26, 13130-13141.

(27) Cayre, O.; Paunov, V. N.; Velev, O. D. J. Mater. Chem. 2003, 13, 2445-2450.

(28) Ohnuma, A.; Cho, E. C.; Camargo, P. H. C.; Au, L.; Ohtani, B.; Xia, Y. J. Am. Chem. Soc. 2009, 131, 1352-1353.

(29) Perro, A.; Reculusa ; S.; Ravaine, S.; Bourgeat-Lami, E.; Duguet, E. J. Mater. Chem. 2005, $15,3745-3760$.

(30) Pawar, A. B.; Kretzschmar, I. Macromol. Rapid. Commun. 2010, 31, 150-158.

(31) Lattuada, M.; Hatton, T. A. Nano Today 2011, 6, 286-308.

(32) Hu, J.; Zhou, S.; Sun, Y.; Fanga X.; Wu, L. Chem. Soc. Rev. 2012, 41, 4356-4378.

(33) Reculusa, S.; Poncet-Legrand, C.; Perro, A. ; Duguet, E.; Bourgeat-Lami, E.; Mingotaud, C.; Ravaine, S. Chem. Mater. 2005, 17, 3338-3344.

(34) Perro, A.; Reculusa ; S.; Pereira, F.; Delville, M-H.; Mingotaud, C.; Duguet, E.; BourgeatLami, E.; Ravaine, S. Chem. Commun. 2005, 5542-5543.

(35) Duguet, E.; Reculusa, S.; Perro, A.; Poncet-Legrand, C.; Ravaine, S.; Bourgeat-Lami E.; Mingotaud, C. Mater. Res. Soc., Symp. Proc. 2005, 847, EE1.1.

(36) Perro, A.; Reculusa ; S.; Bourgeat-Lami, E.; Duguet, E.; Ravaine, S. Colloids and Surfaces A: Physicochem. Eng. Aspects 2006, 284/285, 78-83.

(37) a) Luna-Xavier, J. L.; Bourgeat-Lami, E.; Guyot, A. Colloid Polym. Sci. 2001, 279, 947958. b) Luna-Xavier, J-L.; Guyot, A.; Bourgeat-Lami, E. J. Colloid Interf. Sci. 2002, 250, 82-92. c) Luna-Xavier, J. L.; Guyot, A.; Bourgeat-Lami, E. Polym. Int. 2004, 53, 609-617.

(38) Qi, D-M.; Bao, Y-Z.; Huang, Z-M.; Weng, Z-X. J. Appl. Polym. Sci. 2006, 99, 3425-3432.

(39) a) Schmid, A.; Fujii, S.; Armes, S. P. Langmuir 2006, 22, 4923-4927. b) Schmid, A.; Tonnar, J.; Armes, S. P. Adv. Mater. 2008, 20, 3331-3336. c) Schmid, A.; Scherl, P.; Armes, S. P. Macromolecules 2009, 42, 3721-3728. d) Schmid, A.; Armes, S. P.; Leite, C. A. P.; Galembeck F. Langmuir 2009, 25, 2486-2494.

(40) Yoshinaga, K.; Yokoyama, T.; Sugawa, Y.; Karakawa, H.; Enomoto, N.; Nishida, H.; Komastu, M. Polym. Bull. 1992, 28, 663-668.

(41) a) Negrete-Herrera, N.; Putaux, J-L.; David, L.; Bourgeat-Lami E. Macromolecules 2006, 39, 9177-9184. b) Negrete-Herrera, N.; Persoz, S.; Putaux, J-L.; David, L.; De Haas, F.; Bourgeat-Lami E. J. Nanosci. Nanotechnol. 2006, 6, 421-431. c) Negrete-Herrera, N.; 
Putaux, J-L.; David, L.; Bourgeat-Lami E. Macromol. Rapid Commun. 2007, 28, 15671573.

(42) a) Koppel, D.E. J. Chem. Phys. 1972, 57, 4814-4820. b) International Standard ISO 13321. Methods for determination of particle size distribution. Part 8: Photon Correlation Spectroscopy, International Organization for Standardization (ISO) 1996.

(43) Lin, M.; Chu, F.; Guyot, A.; Putaux, J-L.; Bourgeat-Lami, E. Polymer 2005, 46, 13311337.

(44) Ito, K. J. Polym. Sci. Polym. Chem. Ed. 1973, 11, 1673-1681.

(45) Goodwin, J. W.; Ottewill, R. H. Colloid Polym. Sci. 1979, 257, 61-69.

(46) Wahl, R. U. R.; Zeng, L.; Madison, S. A.; De Pinto, R. L.; Shay, B. J. J. Chem. Soc., Perkin Trans 2: Phys. Org. Chem. 1998, 2009-2018.

(47) Haga, Y.; Watanabe, T.; Yosomiya, R. Angew Makromol. Chem. 1991, 189, 23 - 34.

(48) Dekking, H. G. G. J. Appl. Polym. Sci. 1965, 9, 1641-1651.

(49) Meier, L. P.; Shelden, R. A.; Caseri, W. R.; Suter, U. W. Macromolecules 1994, 27, 1637 1642.

(50) Paria, S.; Khilar, K. C. Adv. Colloid Interf. Sci. 2004, 110, 75-95.

(51) Esumi, K. J. Colloid Interf. Sci. 2001, 241, 1-17.

(52) The only way to create free radicals in water is by chain transfer to monomer within the particles and radical exit. However, if this does occur, it would result in dead polymer chains and neutral radicals that would not be able to provide any colloidal stability to the latex particles.

(53) Unzueta, E.; Forcada, J. Polymer 1995, 36, 1045-1052.

(54) Chern, C-S.; Lin, S-Y.; Chen, L-J.; Wu, S-C. Polymer 1997, 38, 1977-1984.

(55) Colombié, D.; Sudol, E. D.; El-Aasser, M. S. Macromolecules 2000, 33, 7283-7291.

(56) Bourgeat-Lami, E.; Insulaire, M.; Reculusa, S.; Perro, A.; Ravaine, S.; Duguet, E. J. Nanosci. Nanotechnol. 2006, 6, 432-444.

(57) Desert, A.; Chaduc, I.; Fouilloux, S.; Taveau, J-C.; Lambert, O.; Lansalot, M.; BourgeatLami, E.; Thill, A.; Spalla, O.; Ravaine, S.; Duguet, E. Polymer Chem. 2012, 3, 1130-1132.

(58) Prucker, O.; Ruhe, J. Macromolecules 1998, 31, 602-613.

(59) Boven, G.; Oosterling, M.L.; Challa, G.; Schouten, A. J. Polymer 1990, 31, 2377-2383. 
(60) Vanderhoff, J. W.; Vitkuske, J. F.; Bradford, E. B.; T. Alfrey Jr. J. Polym. Sci. 1956, 20, 225-234.

ACS Paragon Plus Environment 


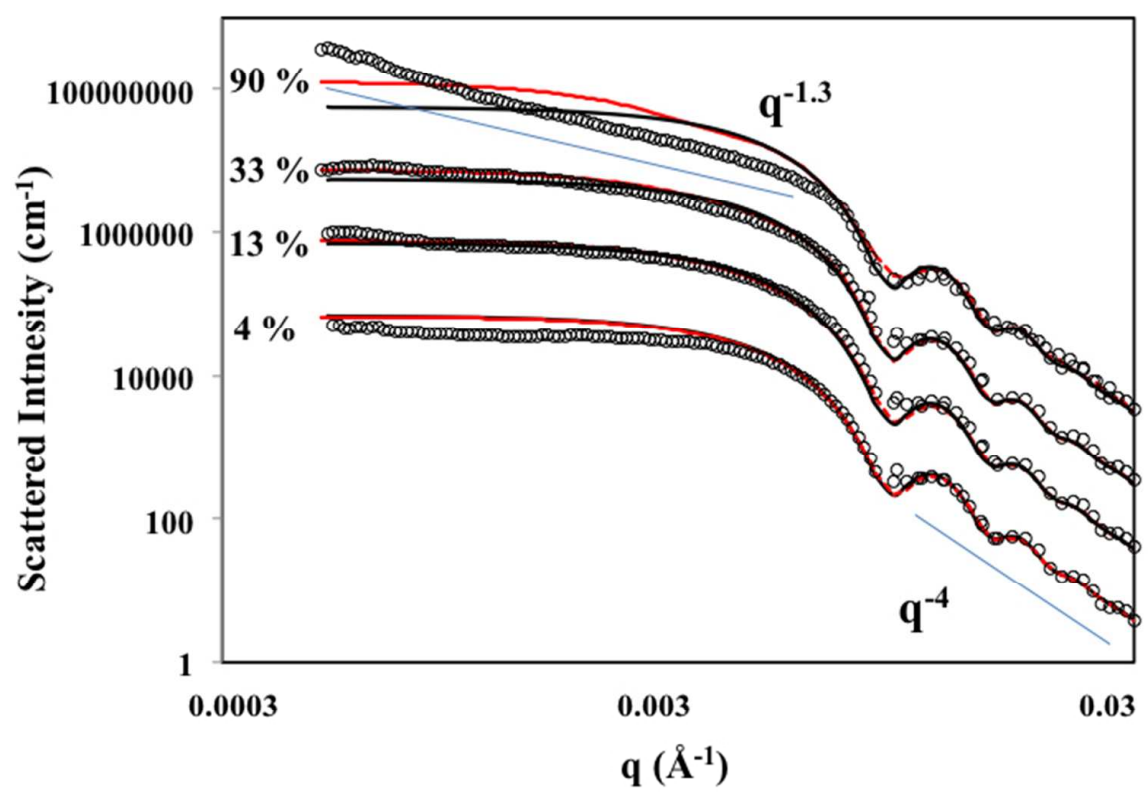

$254 \times 190 \mathrm{~mm}(72 \times 72 \mathrm{DPI})$ 